\title{
Spectral Analysis of Airborne Effluents from Nuclear Facilities and Design of AOTF Spectroradiometer (U)
}

by

E. Villa

Westinghouse Savannah River Company

Savannah River Site

Aiken, South Carolina 29808

D." R. Suhre

L H. Taylor

DOE Contract No. DE-AC09-89SR18035

This paper was prepared in connection with work done under the above contract number with the U.S.

Department of Energy. By acceptance of this paper, the publisher and/or recipient acknowledges the U.S.

Government's right to retain a nonexclusive, royalty-free license in and to any copyright covering this paper, along with the right to reproduce and to authorize others to reproduce all or part of the copyrighted paper. 
This report was prepared as an account of work sponsored by an agenisy of the United States Government. Neither the United States Government nor any agency thereof, nor any of their employees, makes any wanty express or impliéd, or assumes any legal liability or responsibility for the accuracy completeness, or usefulness of any, information, apparatus, product, or process disclosed, or represents that its use would not infinge privately owined rights. Reference lierein to any specific commercial product process, or service by trade name; trademark manufacturer, or otherwise does not nécessarily constitute or imply its endorsement, recommendation, or favoring by the United States Govemment ar any agency thereof The views and opinions of authors expressed herein do not necessarily state or teflect those of the United States Govermment or any agency thereof.

This report has bect reproduced diectly from the best available copy.

Available to DOE and DOE contractors from the Office of Scientific and Technical Infonmation, P.O.Box 62, Oak Ridge, TN 37831,prices ayailable from (615) 576 -840

Avalable to the public from the National Techical Information Service, U.S Department of Commerce, 5285 Port Royal-Road, Springield, VA 22161 


\section{DISCLAIMER}

Portions of this document may be illegible in electronic image products. Images are produced from the best available original document. 


\title{
SPECTRAL ANALYSIS OF AIRBORNE EFHLUENTS FROM NUCLEAR FACIGITIES AND DESIGN OF AOTF SPECTRORADIOMETER
}

\author{
Eliel Villa \\ Savannah River Téchnology Center \\ and \\ D. R Suhre and L. H.Taylor \\ Westinghouse Science \& Technology Center
}

DISTRIBUTION OF THIS DOCLINENT IS UNLIMTER $\pi$ 


\section{TABLE OF CONTENTS}

Section

Page

1. SOURCE SPECTROSCOPY

1.1. Genéral Approach $\quad 5$

1.2 Computer Codes

12.1 QÁSOFT

122 Lab Calc

12.3 GRAMS 386

124 PEAKTB. 12

1.3 Absomtion Measurements 13

1.3.1 Active Measurements.

1.32 Passive Measurements 11

1.4 Atmospheric Effects -14

1.4.1. Temporal Effects 14

1.42 Absoption Effects $\quad 15$

15 Source Gases. 18

1.6 Infrared'Gas Spectra 19

1.6.1. Source Gas Spectra in Reference Library ___ _ - 19

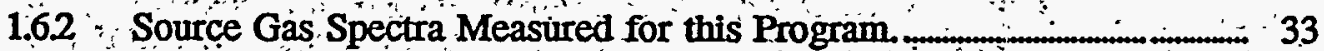

17 Spectral Lines

17.1 Peak Identification 36

172 peak Tables 10

17.3 Highest Non-Interfered Peaks $\quad 42$

1.8 Relative Detection Probability 140.45

181 Thick Plume Detection - 140

1.82 Thin Plume Detection 50

1.9 Conclisions

2. SYSTEMDESIGN AND ANALYSIS $\quad 55$

2.1 - AOTF Performance Arialysis. 55

22 System Layout and Component Selection. 50

2.3 AOTF and Associated Power Supply: 59

2.4 Signal Processing and Sensitivity Analysis. $\quad 61$

3. REFERENCES 


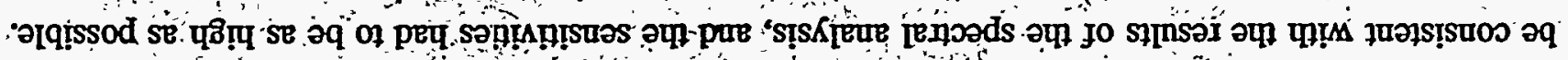

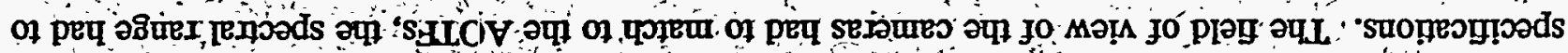

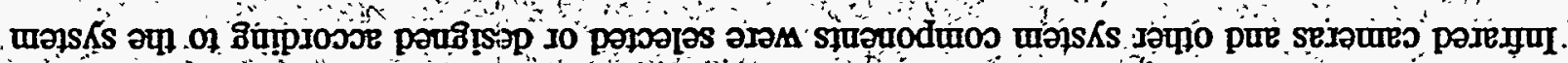

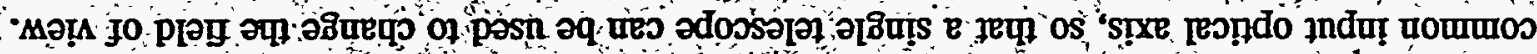

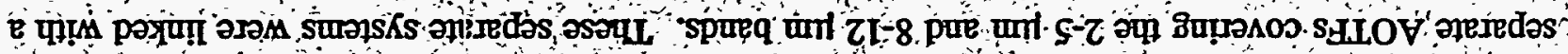

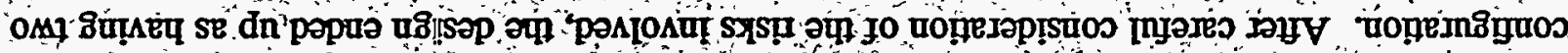



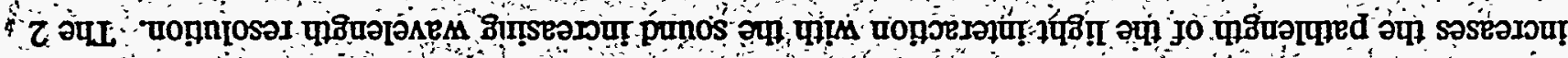

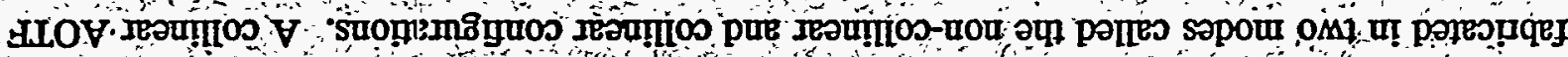

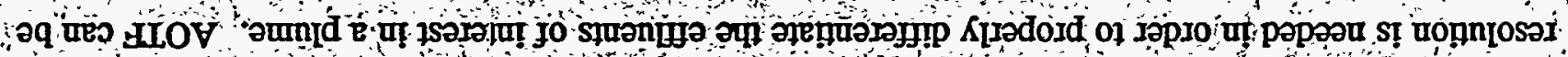

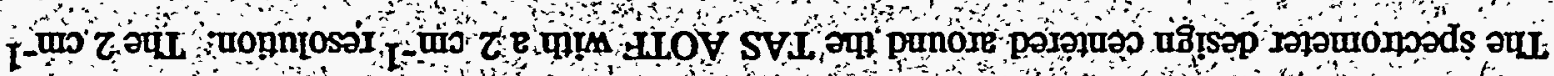

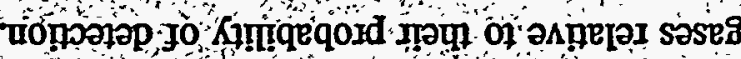

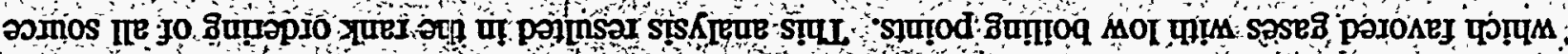



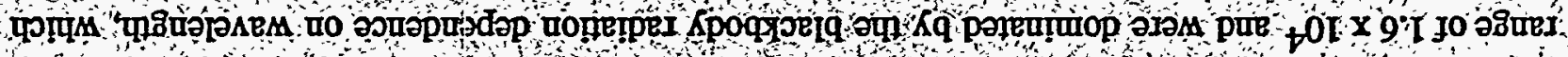

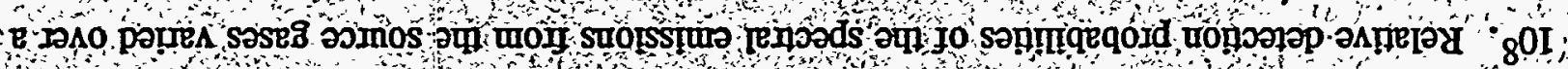

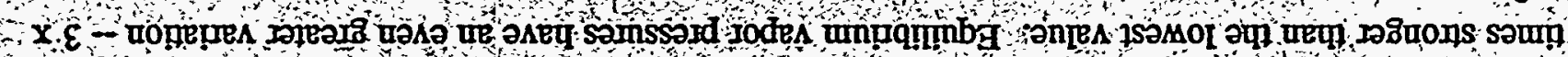

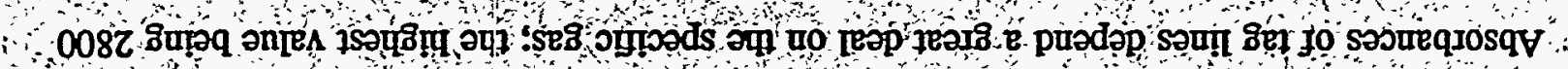

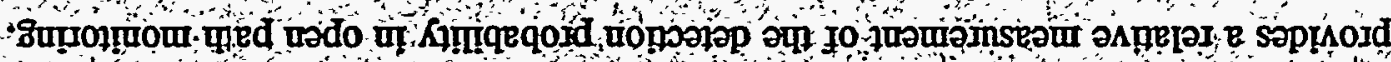

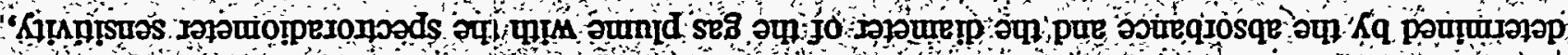

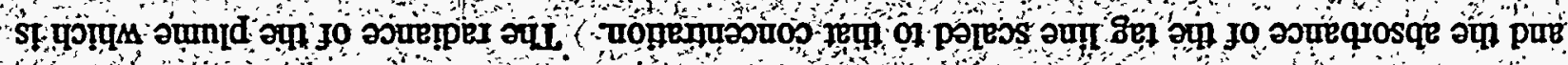



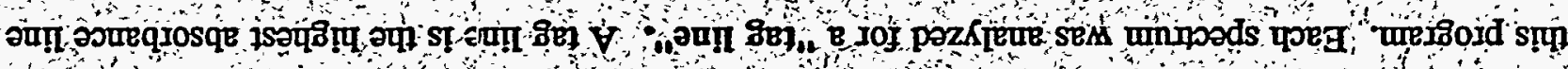

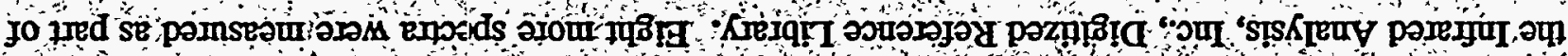

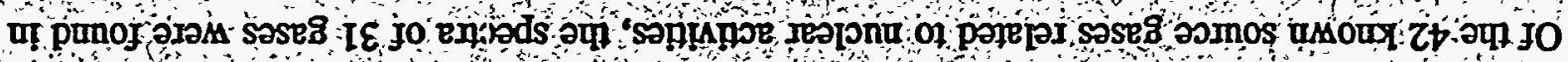
$\therefore$ and and

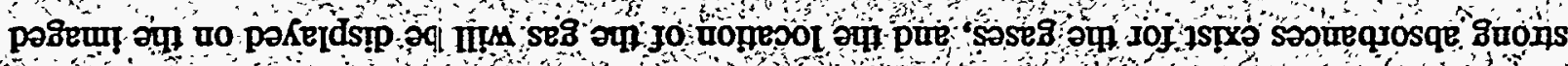

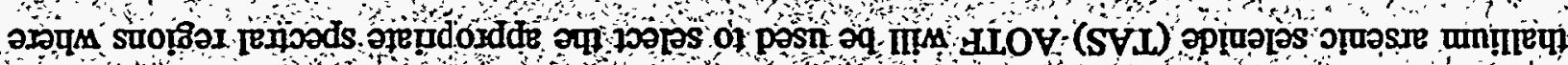

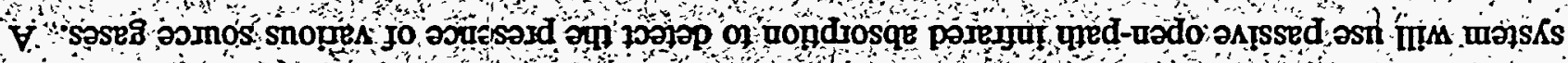

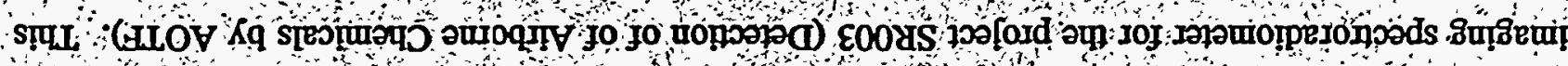

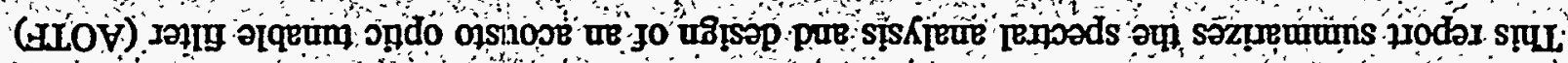

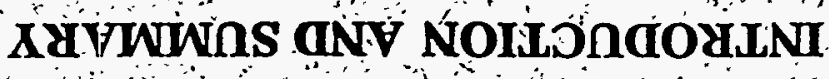


This search resulted in the selection of an Inframetrics 760 camera for the $8-12 \mu \mathrm{m}$ region, and a Cincinati Electronics IRC-160 camera for the $2-5 \mu \mathrm{m}$ band

The spectral image data will be recorded in near real time, and then analyzed in-depth. The analysis consists of adding frames and pixels to increase the senisitivity, and then displaying the location of the detected gas on the image The analysis indicated excellent sensitivities in the $8-12, \mu \mathrm{m}$ band with sensitivites as high as $16 \mathrm{pp}$-m, for such source gases as tributyl phosphate In the 2-5 $\mu \mathrm{m}$ band, the sensitivity was very poor which is due mainly to the lack of room temperature thermal radiation below $3.5 \mathrm{~m}$. Due to the poor sensitivity predictions, along with the scarcity of source gas tag lines in this region, passive open path monitoring is not nearly as viable in the 2-5 um band and it was recommended that the system concentrate only upon the $8-12 \mu \mathrm{m}$ band. 


\section{SOURCE SPECTROSCOPY}

\subsection{GENERAL APPROACH}

The goal of the AOTF Spectroradiometer. System Program is to demonstrate the applicability. of an Imaging Acousto-Optic Tunable Filter (AOTF) to the open path detection of gaseous effluents related to nuclear activities. The optical spectroscopy of the source gases must be known in order to design an optimum system. Gases have spectra which fall into five-wavelength regions: 1

$\therefore$ UV and Visible $(0.2$ to $0.76 \mu \mathrm{m})$ Atoms and homonuclear diatomic molecules have spectra in this region only. Some light molecules also have spectra here.

- Near-IR $(0.76$ to $3 \mu \mathrm{m})$. Most light molecules have spectra here.

- Mid-IR (3 to $6 \mu \mathrm{m})$. Most molecules have spectra here but the lines overlap exterisively, making it difficult to identify molecular species.

- Far-IR (6 to $15 \mu \mathrm{m})$. Richest spectral region for molecular identification:

- Extreme-IR (15 to $1000 \mu \mathrm{m})$. Few molecules have important bands here. Roughy $10 \%$ of molecules have spectra useful for ddentification in the near-IR, $35 \%$ in the mid-IR, $80 \%$ in the far-IR, and $1 \%$ in the extreme-IR.

The chemicals involved in the nuclear operations are fairly well known. They all emit in the infrared region from 2 to $14 \mu \mathrm{m}$. We have spectra for the gieat majority of these gases in a digitized reference library and have measured the spectra for those remaining gases which could be obtained commercially from chemical suppliers.

Each spectrum is analyzed for a "tag line", which is the highest absomance line with a center which does not overlap any atmospheric absorption line. Equilibrium vapor concentrations are then determined and the absorbance of the tag line is scaled to that concentration. This absorbance and the diameter of the gas plume determine the radiance of the plume which combined with the spectroradiometer's sensitivity, is a relative measure of the probability of detection in open path monitoring. With this information the AOTF-based spectroradiometer can be designed for maximum impact on satisfying the program goal."

\subsection{COMPUTER CODES}

Optical spectra are quite complicated, often comprised of several hundred lines of varying strengths and widths,' and depend on external factors such as gas pressure, gas temperature, and spectrometer resolution. They also depend on internal factors such as inoblecular structure, collisional, broadening, and Doppler broadening. To handle the spectra of several gases it is essential to utilize computer codes to manipulate the vast amount of data and to analyze the data for key features which 
uniquely identify each molecular species Four key computer codes for spectra manipulation are déscribed here.

\subsubsection{QASOFT}

A high resolution digitized library of the infrared absorption spectra of gases has been created by Infrared Analysis, Inc in Anaheim, Califonia The libray includes spectra of more than 180 gases, a complete list is given in Table 1 and most of the spectra are avalable in resolutions of $0.125,025,0.5$; 1.0 and $2.0 \mathrm{~cm}^{-1}$ We have the libary of spectra with resolutions of 0125 and $1.0 \mathrm{~cm}-1$

The digitized spectra are provided on 35 in disks in a computer format compatible with the $\mathrm{Lab}$ Calc data processing program described next The digitized spectra are supported by a manual 2 of over 300 pages which presents ail the spectra at four different values of resolution and gives commentaries relevant to the quantitative measurement of the gas spectra.

The spectra in the library cover the range from $500 \mathrm{~cm}^{-1}$ to $3700 \mathrm{~cm}^{-1}$ (except for $\mathrm{HF}$ which has a strong band higher than $3700 \mathrm{~cm}-1$ ) This region is the fundamental infared region where the rotation and vibration of the molecules absoth radiation efficiently there is tittle of value on either side of this region. At higher frequencies there are only overtones which have extriemely small absontion coefficients At lower frequencies there might be good strong rotation lines but because of strong absorption by water yapor they are inaccessible to gases in the open atrosphere.

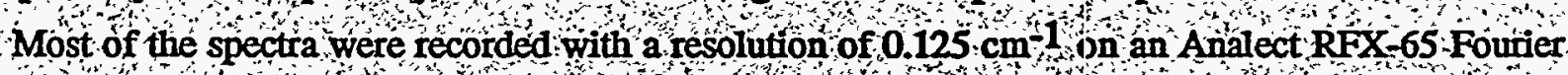
transform spectrometer equipped with a HgCoTe detector. since the full width half maximum of a single abonoton line at nomal temperature and pressure is $-02 \mathrm{~cm}-1$, he spectral details are well xeproduced Some of the spectat usually of heav molecules that do not have spectral fine structure were recorded with a resolution of $0.5 \mathrm{~cm}-1$ on a Digilab FTS 40 spectometer

The appearance of a spectrum (ine intensity and broadening is affected dramatically with pressure To obtain accurate absoption values, the total pressure and gas temperature were kept as close as possible to the conditons encountered in the open atmosphere, 1 atmosphere and $70 \mathrm{~F}$ These conditons were met by adding just enough of each trace gas to give an absorbance near 0.1 in one atmosphere of nitrogen of oxygen at $70 \mathrm{~F}$. For most gases, the accuracy of the absorption coefficient and of the concentration pathength product is thought to be around $5 \% 3$

Included with the QASOFT digitized reference library is the PROCESS program which generates low-resolution namely $0.25,0,50,1,2,0 \mathrm{com}$, spectra from the $0.125 \mathrm{~cm}-1$ database It also generates spectra at values of the concentration-path length, i.e. the ppin-m, different from those at which the spectra were méasured, although the new $\mathrm{ppm}-\mathrm{m}$ values should generally be no greater or less than a factor of eight from the experimental values. The program performs the proper scaling, smoothing, shifting, and interpolation necessary to accurately portiay the spectral features of infrared 


\section{gass spectra as they would appear under actual instrument conditions at the different resolutions and} concentration values.

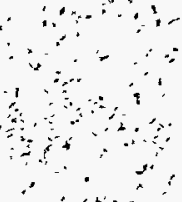


Table 1. The 180 gases in the Digitized Spectra Reference Library.

Hydrocarbons, C1-C5

Acetylene

1,3 Butadiene

n-Butane.

Cyclo. pentene

Cyclopropane

Ethane

Ethylene

Isobutane

Isobutylene

Isoprené

Non-Aromatic Hydrocarbons, C6 \& Up

Alpha-Pinene

Beta-Pinene.

Cyclo hexáne

Cyclo héxene

n-Heptane:

n-Hexane

Aromatic Hydrocarbons

Benzene

Ethyl benzene

Isopropyl benzene

Mesitylene

n-Propyl benzene

Styrene

Hydrides

Ámmonia

Ársine

Hydrazine

Hydrogen bromide

Hydrogen chloride

Oxides and,Peroxides

Carbon dioxide

Carbon monoxide

Ethylene oxide

Furan

Organic Acids

Acetic acid, mostly monomer

Acetic acid, monomer \& dimer

Acrylic acid, mostly monomer

Acrylic-acid, monomer \& dimer

Aldehydes

Acetaldehýde

Acrolein

Benzaldehyde

in-Butyraldehyde

Ketones

Acetone

2-Butanone

Di-ethyl ketone

Alcohóls
Methane

2-Methyl butane

2-Methyl-2-butene:

3-Methyl-1-butene

in-Pentane

1-Pentene

2-Pentene

Propane

Propylene

2-Methyl peritane

3-Methyl peritane

2-Methyl-1-pentene

2-Methyl-2-pentene

4-Methyl-1-pentene

n-Octane

Tertiary butyl benzene

Toluene

1,2,4 -Trimethyl benzene

0-Xylerie

m-Xylene

p-Xylene

Hydrogen fluoride

Hydrogen iodide

Phosphine

Water

Hydrogen peroxide

Ozone

Propylene oxide

Tetrahydrofuran

Formic acid, moriomer

Propionic acid, mostly monomer

Propionic acid, monomer \& dimer

Crotonaldehyde

Formaldéhyde

Propionaldehỳde

Methyl isobutyl ketone

Methyl vinyl ketone 
Allyl alcohol

n-Butyl alcohol Ethanol

Esters

( n Butyl acetate

Ethyl acetate

Ethyl acrylate

Ethyl butyrate

Ethyl formate

Methy i acetate

Ethers

Di-ethỳl ether

Di-isop ropyl ether

Di-methyl ether

Inorganic Nitrogen-Molecules

Dinitrogen pentoxide

Hydrogen cyanide

Nitric acid

Nitric oxide

Organic Nitrogen Molecules

Aceto nitrile

Acrylo nitrile

Dièthyl amine

1,1 Dimethyl hydrazine

Methỳ ámine

Methyl nitrite

Sulfuir-Cóntaining Molecules

Carbon disulfide

Carbonyl sulfide

Dimethyl sulfide

Hydrogen sulfide

Methyl mercaptan

Halogenated Methanes

Bromochloromethane

Bromoform

Bromo methane

Căbon tetrachloride

Chloro difluoro methane

Chloroform

Chloro methane

Halogenated Ethariès.

1-chloro-1, 1 difiuoro ethane

Chloro ethane

1,2 Dibromo ethane

1,1 Dichloro ethane

1,2 Dichloro ethane

1,1 Dichloro-1-fluoro ethane

Hălogenated Ethenes

Chloro trifluoro ethylene

cis-1,2 Dichloroethylene

Tetrachioro ethylene

Halogenated Benzenes

Bromobenzene :
Isobutanol

Isopropanol

Methanol

Methyl acrylite

Methyl formate

Methyl methicrylate

n-Própyl acetate

Vinyl acetate

Ethyi vinyl ether

Methyl vinyl ether

Nitrogen dioxide

Nitrogen dioxide \& tetroxide

Nitrous acid

Nitrous oxide.

Nitro benzenê

Nitro ethane

Nitro methane

Nitroso benzene

Peroxy acetyl nitrate

Sulfur dioxide

Sulfur hexaflioride

Tetrahydrothiophene

Thiophene

Chloro trifluoro methane

Dichloro difluoro methane

Dichloro methane

Dibromomethane

Iodo methane

Tefrafluoio methane

Trichoro fluoro methane

Trichlorotriflionoethane

1,2 Dichloro letrafluoro ethane

$1,1,1,2$ Tetrachloroethane

1,1,2,2 Tetrachloroethane

1;1,1 Trichloro ethane

1,1,2. Trichloro ethane

Trichloro éthylene

Vinyl chloride

Vinylidene chiloride

m-Dichloro benzene 


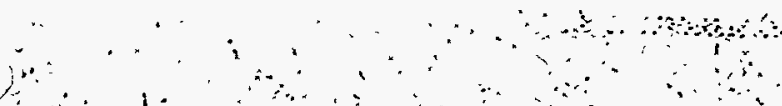

\section{WSRC-TR-95-0136}

AOTFSR7 doc

032095

\section{Chloro bénzene \\ 2-Chlorotolúene \\ 4-Chlorotoluene}

Miscellaneous

Acetyl chloride

Boron trichioride

Carbonyly fluoride

1,2 Dichloropiopane

1,3. Dichloropropane

Exxon 87 gasoline

\section{o-Dichlorö benzene \\ p-Dichloro bizizene \\ Furo benzene}

K-1 Kerosené

Perfluóro butarie

Phosgene.

Phosphonus tichloride

Silicon tetrafluótide

1,2,3 Trichioiopropane

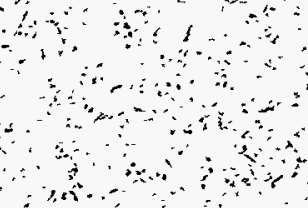




\subsubsection{Lab Calc}

Lab Calc is a spectra manipulation program from Galáctic Industries Corp. in Salem, New Hampshire. The program has several features; some of which are:

$\therefore$ Extensive data processing capabilities

- Compreheńsive peak editing and area calculation

- Convenient import and export of spectroscopic data

Up.to 30 levels of contour lines in eight colots

- Threeddimensional graphic capabilities

$\because$ What you see-is-what-you get plotting

C Fast display zooming capabilities

Additional programs which extend the data processing capability with some sophisticated quantitative analysis capabilities such as Partial Least Squares 4 are avalable but were not purchased since their applicability to AOTF-based spectroradiometers is not apparent:

This program can analyze overlapping spectral bands as a sum of fully-resolved ideal peaks.

Peaks can be modeled as Gaussian, Lorentżian, or mixed Gaussian-Lorentzian The modeled peaks are adjusted for the best fit with the Levenberg-Marquardt algorithm. 5 tabular report of the peak deconvolution analysis gives the center wavelength width height and area of each peak

Baselines are adjustable with operator selected approaches which vary from simple two-point linear baselines to sixthorder polynominal curves Alternatively, the baseline can be adjusted automatically by the program which eliminates the need to prepocess nost data Savitsky-Golay 6 smoothing is available to reduce the effect of noise spikes and to provice spectral derivatives.

When mixtures are encountered pure spectra of the lindividual components can be subtracted from the mixture spectra thereby yielding the underlying peaks and simplifying the identification of the individual components. In this subtraction mode the concentration path lengths of the individual components are adjusted to give the best fit to the mixture spectra

Lab Calc and Process are both written in the Array Basic programming language which is a : highly optimized, extremely fast array oniented language which is integiated with and takes advantage of the display graphic environment. The lánguage includes almost 200 statements and Functions. The array sizes are limited only by computer memory; the Lotus/ntel expaniled memory standard is used to make megabytes of memory available for data manipuiation. Typical tinnings on an AT with a $6 \mathrm{MHz}$ coprocessor are:

- 4 seconds to invert a $30 \times 30$ matrix of random numbers

- 2 seconds to multiply two 32 k point arrays

- 2 seconds to convert 8;000 point spectrum from transmission to absorbance

This language; as well as the source program, is provided with Lab Cale. 


\subsubsection{GRAMS/386}

GRAMS1386 is the new spectra manipulation program from Galaclic Industries Corp. It provides all the features of Lab Calc under the friendy Microsoft windows graphical user interface. This totally new product is a true 32 bit program which takes full advantage of 80386 and 80486 processors. For computationally intensive applications GRAMS/386 runs from two to ten times faster than $\mathbf{L a b}$ Calc. In addition GRAMS/386 incoporates an innovative hierarchical relational database designed to efficiently manage the huge quantities of raw data generated in spectroscopic measurements.

GRAMS/38 6 includes new documentation, inproved mem dialog, and a frendier user interface. The use of Windows Dynamic Data Exchange (DDE) and Galactic's Array Basic Control Labuage (ABC) simplify interfacing with instrumentation Array Basic application ptograms such as curvefit Spectra subtraction and baseline corrections have been inproved Furthermore, peak marks are placed so that they do not overlap and connecting lines are given that indicate each peak Font colors of the lines and labels are automatically chosen for maximum contrast with the trace box color GRAMS/386 a new generaton product which largely has backward compatibility to Lab Calc However, GRAMS/386 uses an enhanced file format that is not compalibe with Lab Cale This Incompatibility is the reason that Lab calc was used for all the results given here since at the time they were obtained the QASOFT Atlas of spectra existed only in the old format This limitation is being temoved with the eminent telease of a GRAMS/386-compatible QASOFT At as of spectra

\subsubsection{PEAKTB}

The Peaks Table given by Lab Calc is ordered by wavelength and includes some peaks which are obviously not ture peaks, ef negative peaks which result from noise or peaks with negative areas due to incorrect baseline determination To obtain móre useful tables of spectral peaks, a Fortrant7 program PEAKTB; was written to read the Lab Calc generated table and generate two new tables.

The first table, called the Modified Peaks Table, is formed by eliminating all peaks with absorbances less than an operator-specified value and all peaks, with abisortances above another, operator specified value (high absorbance values 7 occasionally occur at the very ends of the wavelength range being measured and result from instrumention error). This table is still ordered from large to small wavelengths and is simply a cleaner version of the original Peaks Table.

The second table, called the Sorted Peaks Table, is formed by usirig the straight insertion technique to order the first table from the highest to the lowest absorbance value Although straight insertion is an $\mathrm{N}^{2}$ routine for $N$ elëments, and nominally should be used for small $N$, say $N<50$, the program runs very fast on a 386 computer and there is no apparent penalty, for using this "slow" algorithm. 
The Modified Peaks Table is most useful for locating atmospheric interferences to an absorption line of a gas of interest. The Sorted Peaks Table is most useful for fincling the highest absorbance lines for a gas of interest, ie those lines most useful for high sensitivity. Both tables contain:

Peak Number

Peak Absorbance

Wavelength of Peak in im

$\therefore$ Left Edge in cm-1

Peak Location in cm-1

- Right Edge in cm-1

- Line Width in cm:1

$\because$ Line Area in cm-1

Furthermore, both tables can be linearly scaled to any concentration-pathength product

\subsection{ABSORPTION MEASUREMENTS}

\subsubsection{Active Measurements}

In active measurement a hot source is used such as a SiC glower is used for doentification and quantification of gases in the atmosphere. The radiance of the source is determined by the temperature of the SiC Tod. The temperature of the source is held around $1550 \mathrm{~K}$ ard considered to be a blackbody radiator. A bistatic configuration is used in which the radiaton source and detector are at different ends The airborne effiuents are detected and analyzed duning the crossing of the optical path of the instrument The radiation intensity attenuated by the effluent plume is determined by Bers law and given by the equation



where $I_{0}\left(T_{s}, v\right)$ is the background radiation calculated with the planck function evaluated at the source temperature, $T_{S} \alpha(v)$ is the absorptivity of the 1 th component, $C$ is the concentration of the th component and $\mathrm{L}$ is the pathlength. This equation does not take into arcount other possible participants such as plume emission, attenuation and emission by the atmosphere, scattering and reflection of radiation by other sources besides the background and the plume. The absorbance calculated from the Beer's law is given by the equation

$$
A b s=-\log \left(\frac{I(v)}{I_{0}(v)}=a(v) C L\right.
$$


Other factors such as atmospheric pressure and resolution of the instrurnent have not been added to the equation but are expected to affect the linearity of the Beer's law.

\subsubsection{Passive Measurements}

In many cases, hot sources such as the Sic glower cannot be used for the detection and characterization of effuents in a plume. Passive'measurements become the only alternative in order to gain an insight of the chemical composition Passive measurements are made against a background which in general has a similar temperature to the plume Under these conditions, detection and quantification of the effiluents is difficult Beers law does not provides an accurate representation of the concentration - pathiength product. The net radiation from the effilients in the plume in power per unit area per steradian per wavenumber is given by

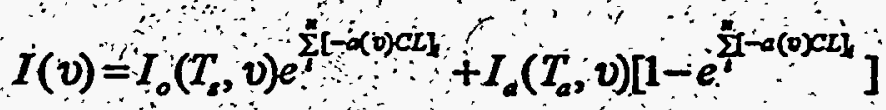

where $I_{a}$ is the plán function evaluated at the effluent plume temperature, $T_{a}$. The absorbance from this equation is given by:

$$
A b s=-\ln \left[\frac{I-I_{a}}{I_{0}-I_{a}}\right]
$$

\subsection{ATMOSPHERIC EFFECTS}

\subsection{Temporal Effects}

There are three basic temporal frames for atmospheric effects. 8 ishort time effects are caused by the wind moving small-scale refractive index inhomogeneities through the observation patio The effect is a $20 \%$ fiuctuation in the intensity which increases at humidities over $70 \% .9$ The scintillation frequency is given by

$$
f=(2 \mathrm{~L})-1 / 2 v_{W}
$$

where is the wavelength, $L$ is the observational path length, and $v_{w}$ is the wind velocity orthogonal to the line of sight. The fluctuation amplitude can be reduced, i.e., averaged out, with radiation collecting apertures larger than $(L)^{1 / 2}$, e.g., for apertures larger than $20.5 \mathrm{~cm}$ for $14 \mu \mathrm{m}$ radiation over $a^{-} 3 \mathrm{~km}$ path length. Furthermore, the atmosphere is essentially "frozen" by taking reasurements over short time periods, on the order of 10 ms or less.

The medium time effect is beam wander caused by large blobs of perturbed refractive index moving through the line of sight. The angular deviation is roughly independent of wavelength but is 
proportional to $\mathrm{L}^{1 / 2}$ over a $3 \mathrm{~km}$ path length, the beam wander is 8 frad. The frequency of this disturbance is on the order of $1 \mathrm{~Hz}$. Fortunately, beam wander does affect sensitivity and is too small to significantly affect plume location.

The long time effect is simply due to the atmosphere rot being a homogeneous gas For times longer than 30 seconds, atmospheric constituents at a particular location change due to wind, turbulence, convection, and/or diffusion This effect can be an advantäge by moving distant trace gases of interest into the spectroradiometer field of view.

There is one more temporal effect the limitation on inpoving acciracy by averaging many measurements. If the individual measurements are independent the siginals will add directly but the uncorrelated noise will add only as a root mean square thereby improvilg the signal to-noise ratio However, temporally spaced measurements of the atmosphete are not riccessarily independent Recent measurements are inconclusive in that published $L$ dar (Light detection and ranging) measurements show a temporal correlation for 100 seconds which limits the mprovenent obtainable by this technique to about 5 - fold with little improvement obtained by averaging more than 100 measurements 10 in contrast recent measurements at the Los Alamos National Laboratory with their Lidar system show no evidence of temporal comelation 11

\subsection{Absorption Effects}

There are two general types of absoption continumang and line. The largest continum absomption is from water vapor in the 7 to $30 \mu \mathrm{m}$ region mo continum an ses from mixtures of monomers and dimers, and is the result of overlapping wings of many broad lines whose centers are outside the continuum region 12 Line absorption causes spectral interference when absoption lines of one gas masks an absorption line of a trace gas it is a serious problem which has not been completely solved Present technology can identify up to 10 thooughly mixed minotity speies.

These absorptions limit the measurement range for trace gases and restrict the most useful infrared regions to the nine transmission windows in Table 2 where window IX is only partially transmitting 1,13 
Table 2. The nine infrared atmospheric transmission windows through which long-path monitors must operate:

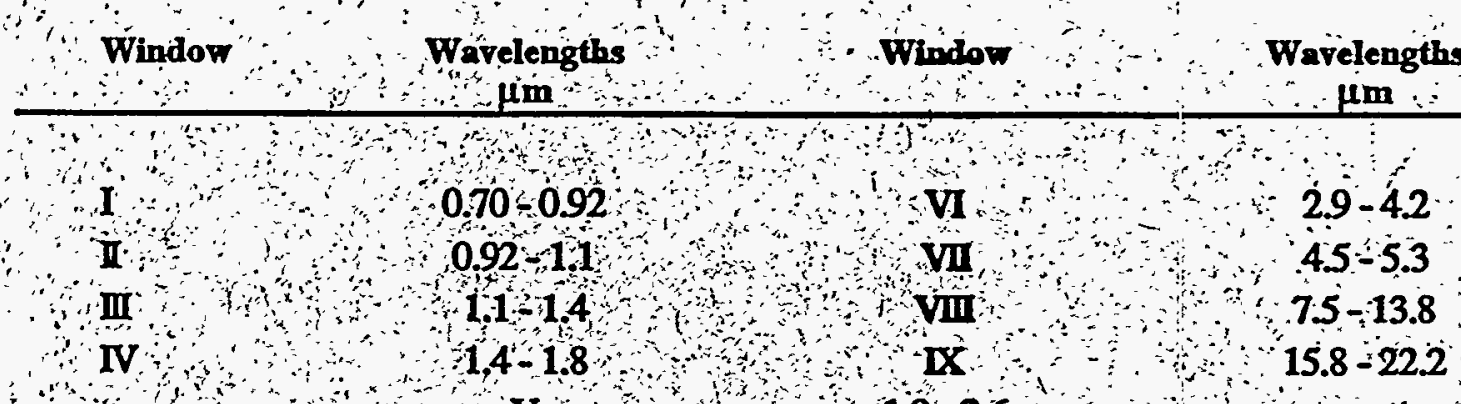

The origin of these atmospheric transmission windows lies in the absorption characteristics of the three most common infrared absorbing atmospheric gases These gases and their nominal concentrations are given in Table 3 Their spectra obtained from the Hinst library are shown in Figure 1. During experimental measurements, Beer's law is obeyed at conceniration-pathilength products leading to a maximum absorbance of 0.1 to 0.2 Therefore, their atmospheric absoibances must be scaled to the value conresponding to their atmospheric concentration

Táble 3. Five normal atmospheric constituents canse virtually all itmospheric absorption effects.

Chemical Name Formula Concentration; ppm

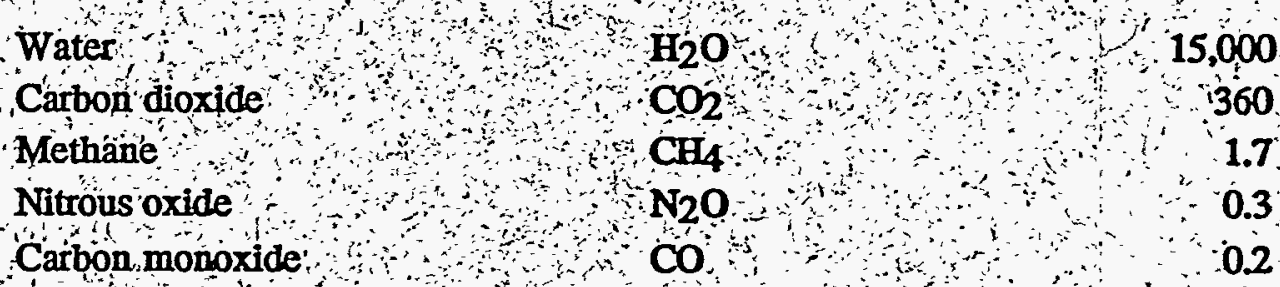

The other two major atmospheric constituents, nitrous oxide and csirbon monoxide, must also be considered since their atmospheric concentrations occasionally mask trace gases by spectroscopic interference. All other gases have such low concentrations, $<27 \mathrm{ppb}$, 14 that they need not be considered except in special cases of spectral interference.

$\mathrm{O}_{2}$ and $\mathrm{N}_{2}$ have high concentrations but extremely weak infrared absorption since they are homonuclear diatomic molecules. 

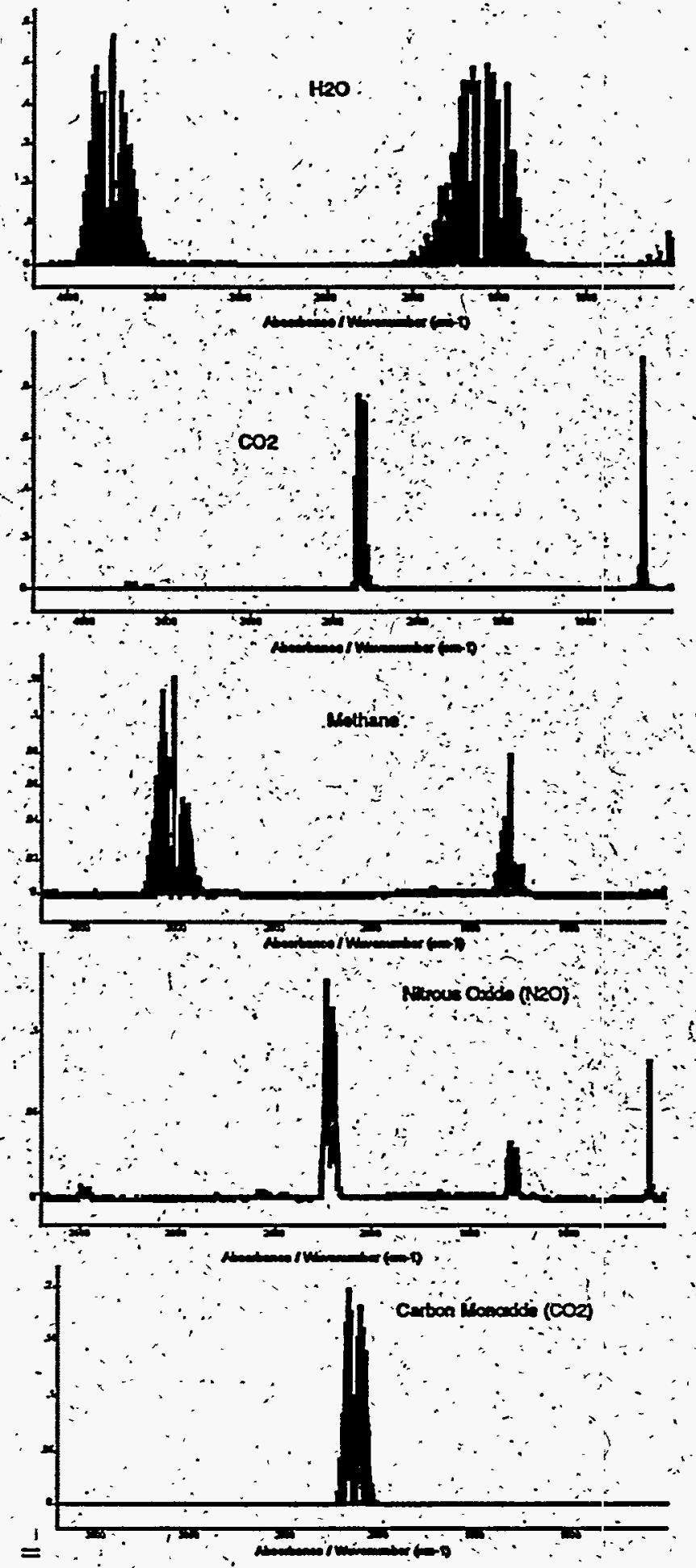

Figure 1 - These five atmospheric spectra determine the transinission windows and most of the spectra interferences: 


\subsection{SOURCE GASES}

In a simulated gas release, several infrared-emitting afr toxic evaporation rates were measured at the Savannah River Site (SRS) and given in Table 4 . A list of 42 gases is given in Table 5. The Chemical Abstract Service (CAS) Registry Number are from $P$. Howard and $M$ Neal is The preferred name, from the same reference is given with an occosional second name in parentheses, except for sulfamate which has a long preferred name

We have three sources for infrared spectra of gas vapors (1) the 180 gas Digitized Reference Library, (2) spectra measured specifically for this poogen by Philip Hanst at Ińfrared Analysis,Inc.,


used for gases not included in Source 1 These two sources are prefertisd because the spectra are digitized and povided on computer disks, Source 3 encompasses a large number of gases but does not include any of the 42 gases not available from the first two sources The spectra source for each gas of interest is included in Table 5

Of the 42 molecules, we have 31 in the Digitized Reference $L$ brary which were measured with

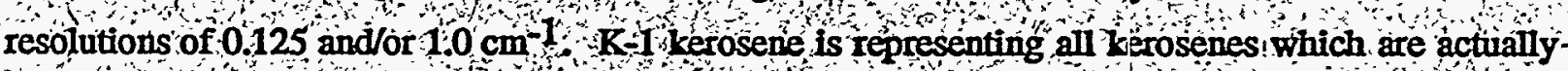
different mixtures with exact mixture ratios depending on the manufacturer bight other gas spectra were measured for us with 0.5 cm 1 resolution by $\mathbf{P}$ Hanst Infrared Analysis Inc.

Of the three gases for which we have no spect hy droxylamin nitrate would probably dissociate

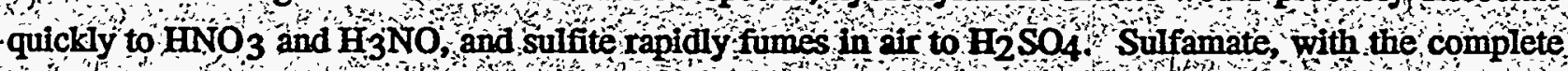
chemical name of Sulfamic acid monoammonium sat must have vet low vapor pressure, rapid dissociation, or rapid reaction since we have not been able to obtain dala on this gas species. It is unlikely that these three gases would exist in measurable concentrations in expected scenarios. They were therefore eliminated from further consideration. 
Table 4. Infrared-emitting air toxic from a simulated release.

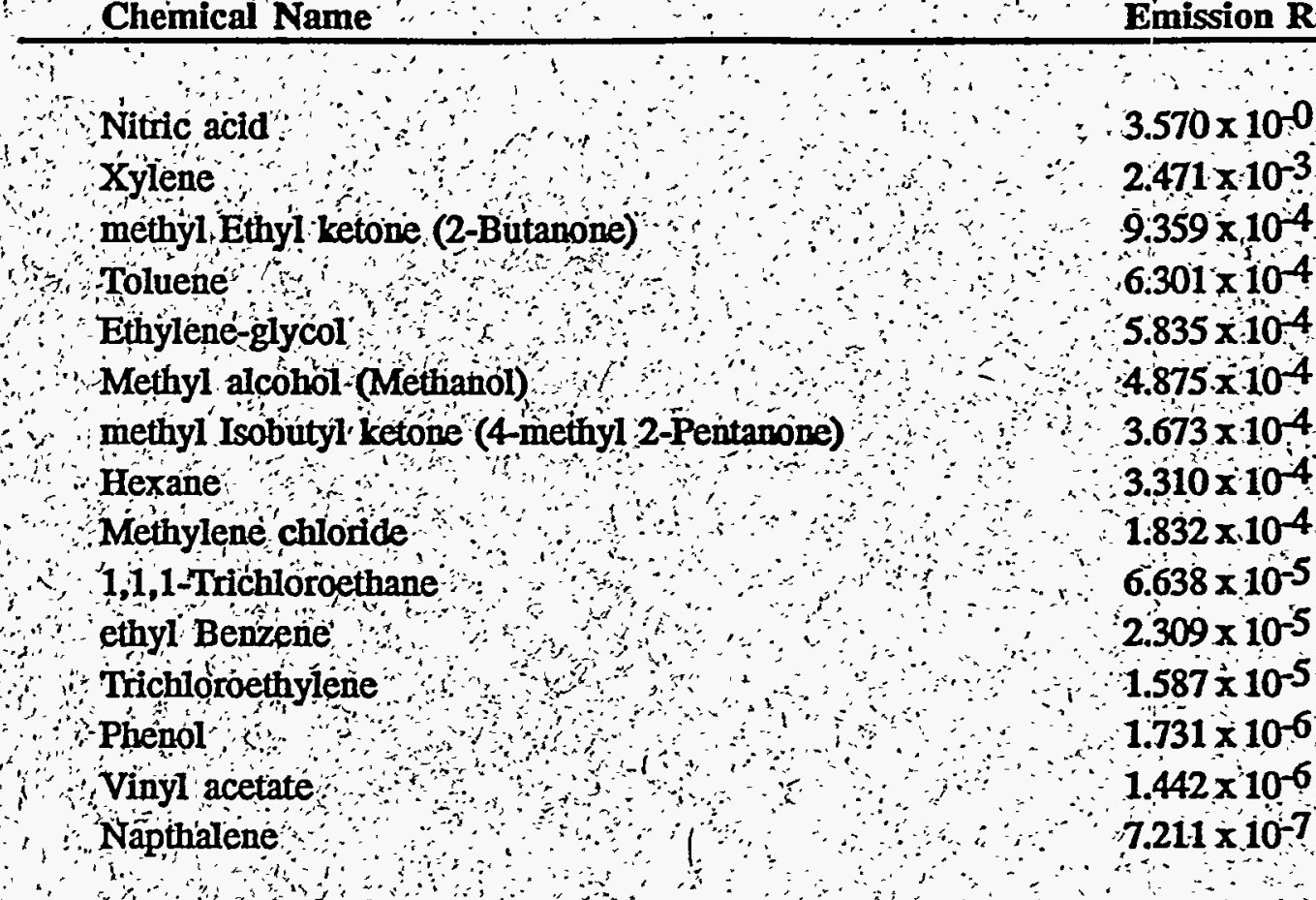

\section{1.6 INFRARED GAS SPECTRA}

\subsubsection{Source Gas Spectra in Reference tibiary}

The effect of measuring spectra at different resolutions is illustrated in Figure 2. As the measured spectra is broadened with increasing resolution, the absotbance of an isjlated peak much narrower than the resolution is reduced in direct proportion to the resolution for lines with widths close to the resolution, the absorbance will also decrease with increasing resolution but slower than linearly. Finally, the absorbance of lines much broader than the resolution are essentially unchanged. $A$ commonly occuring case is a narrow line in close proximity to several pther lines in this situation, Increasing the resolution may decrease or increase the absorance since the increased resolution reduces the narrow line absorbance but encompasses more of the adjacent lines.

Since heavy molecules have primarily broad lines or closely spacel narrow lines, and the optical throughput of a spectroradiometer is inversely proportional to the resolution, $2 \mathrm{~cm}^{-1}$ resolution is a reasonable choice For an AOTF-based spectroradiometer, the time needed to scan a region or band of : wavelengths is proportional to the resolution. Again, $2 \mathrm{~cm}^{-1}$ is a reasoriable compromise between speed and optical throughput versus accuracy, and is the value for most of the spectra given herein 


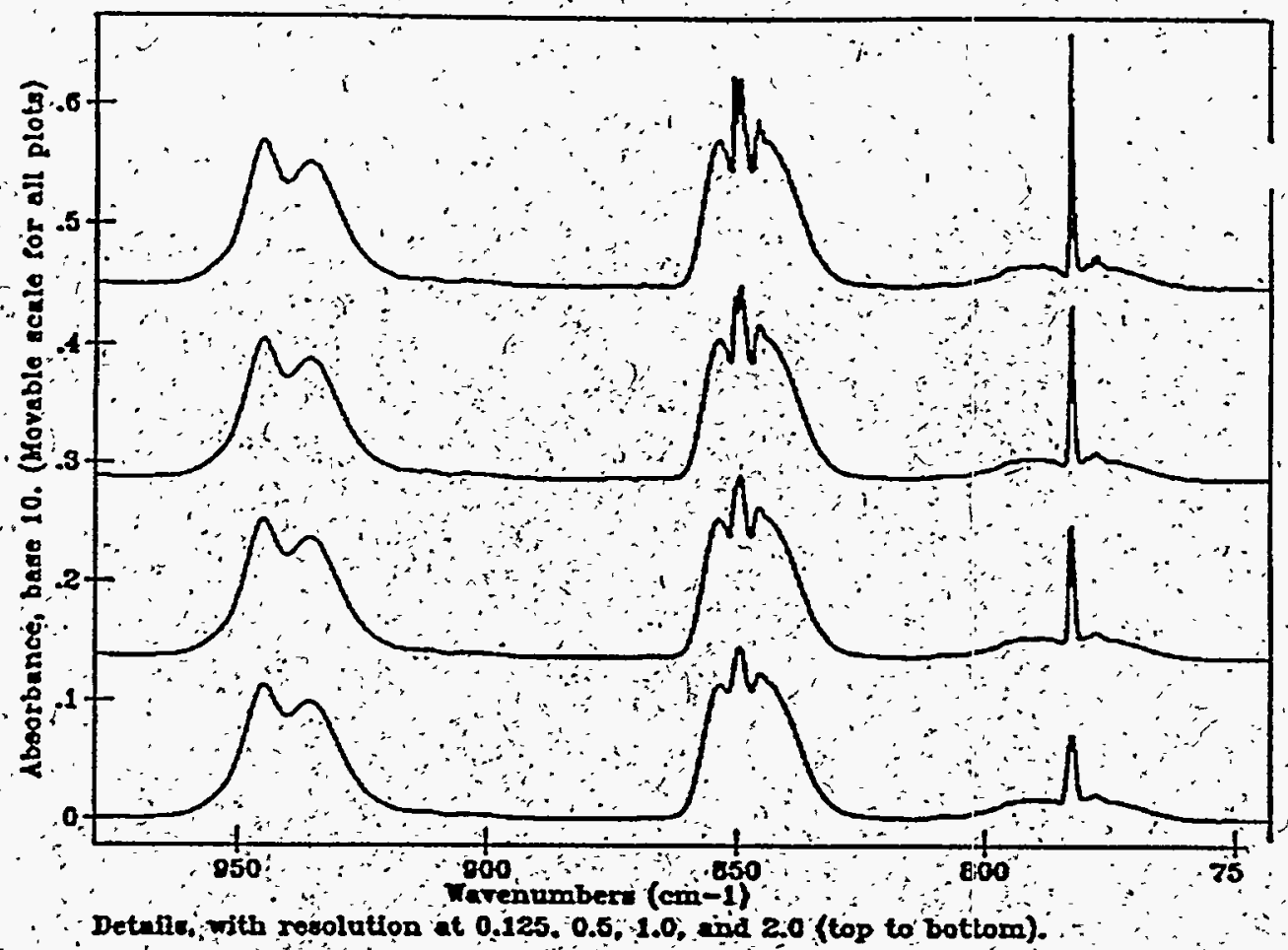

Figure 2- Increasing the resolution decreases the absorbance of narrow lines but has little effect on broad lines or on closely spaced narrow lines as shown by this Trichoroethylene spectra shown, from top to bottom, at resolutions of $0.125,0,5,1.0$, and $2.0 \mathrm{~cm}^{-1}$.

Of the 31 source gases in the Digitized Reference Library, 29 were measured at $0125 \mathrm{~cm}^{-1}$ resolution and could be properly modified to simulate spectra measurements at $2 \mathrm{~cm}^{-1}$ resolution :Tyo gases, nitrous acid and phosphorous trichloride, were measured at $1.0 \mathrm{~cm}^{-1}$ resolution and therefore could not be properly modified to simulate measurements at $2 \mathrm{~cm}^{-1}$ resolution. The spectra of these 31 source gases are presented in Figures 3 through 12 
Table 5: Many chemicals are associated with the processing of industrial materials.

CAS

Spectra Source
Chemical Name Formula





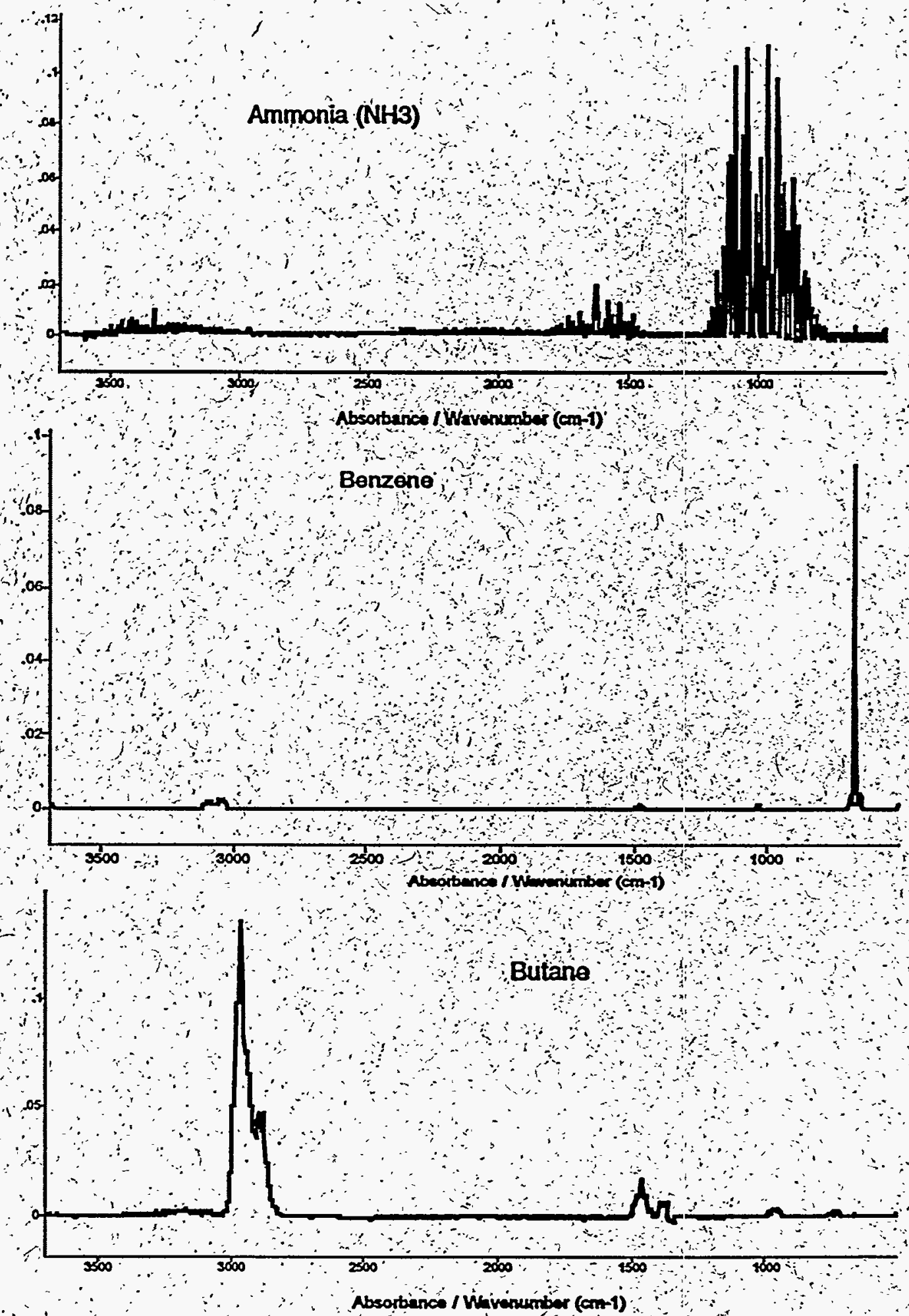

Figure $3-$ Spectra of Ammonia (85), Benzene (20), and Butane (151): 

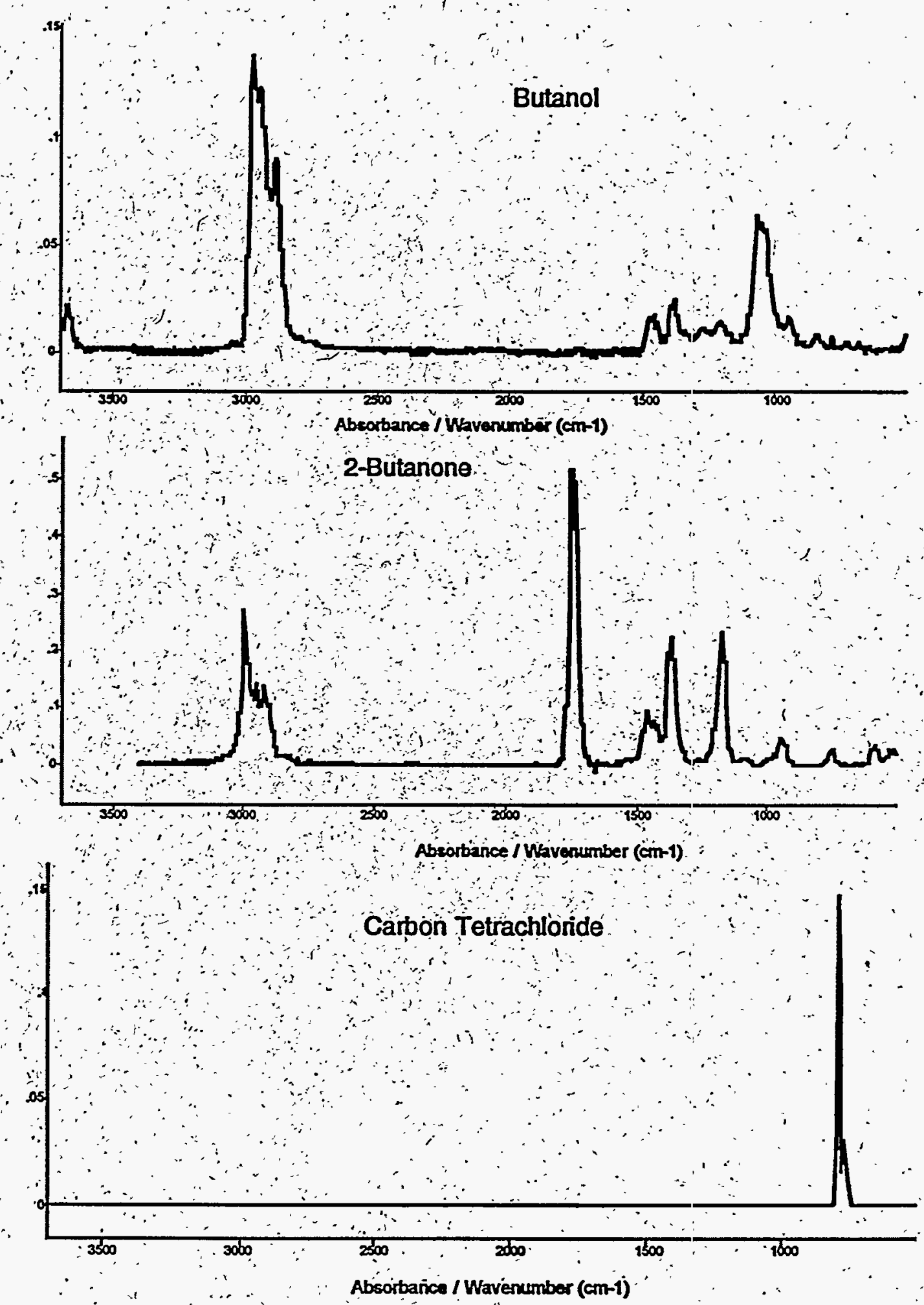

Figure 4-Spectra of Butanol (300), 2-Butanone (762), and Carboin tetrachloride (27). 
WSRC-TR-95-0136

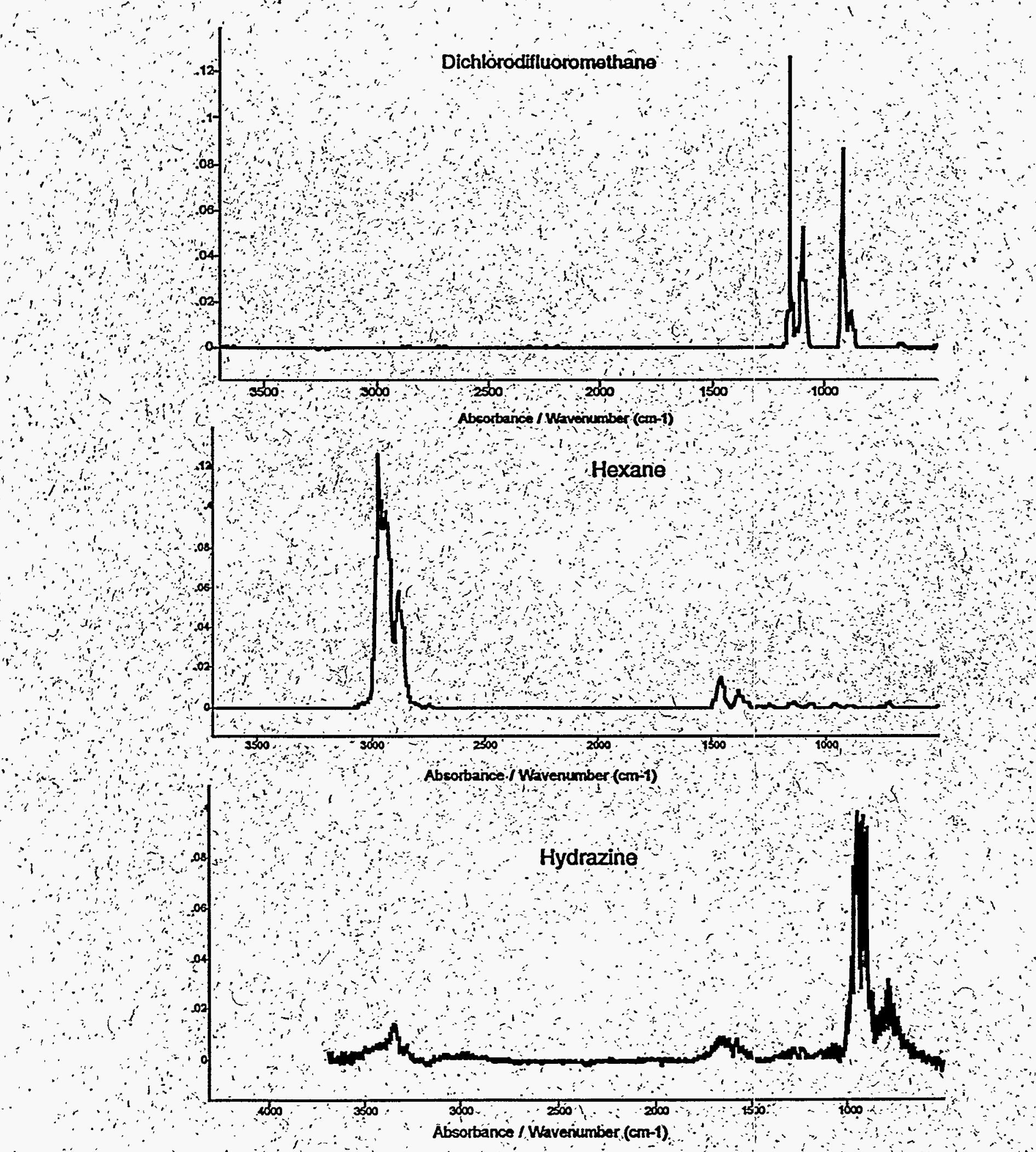

Figure 5 - Spectra of Dichlorodifluoromethane (20), Hexane (121), and Hydrazine (400) 

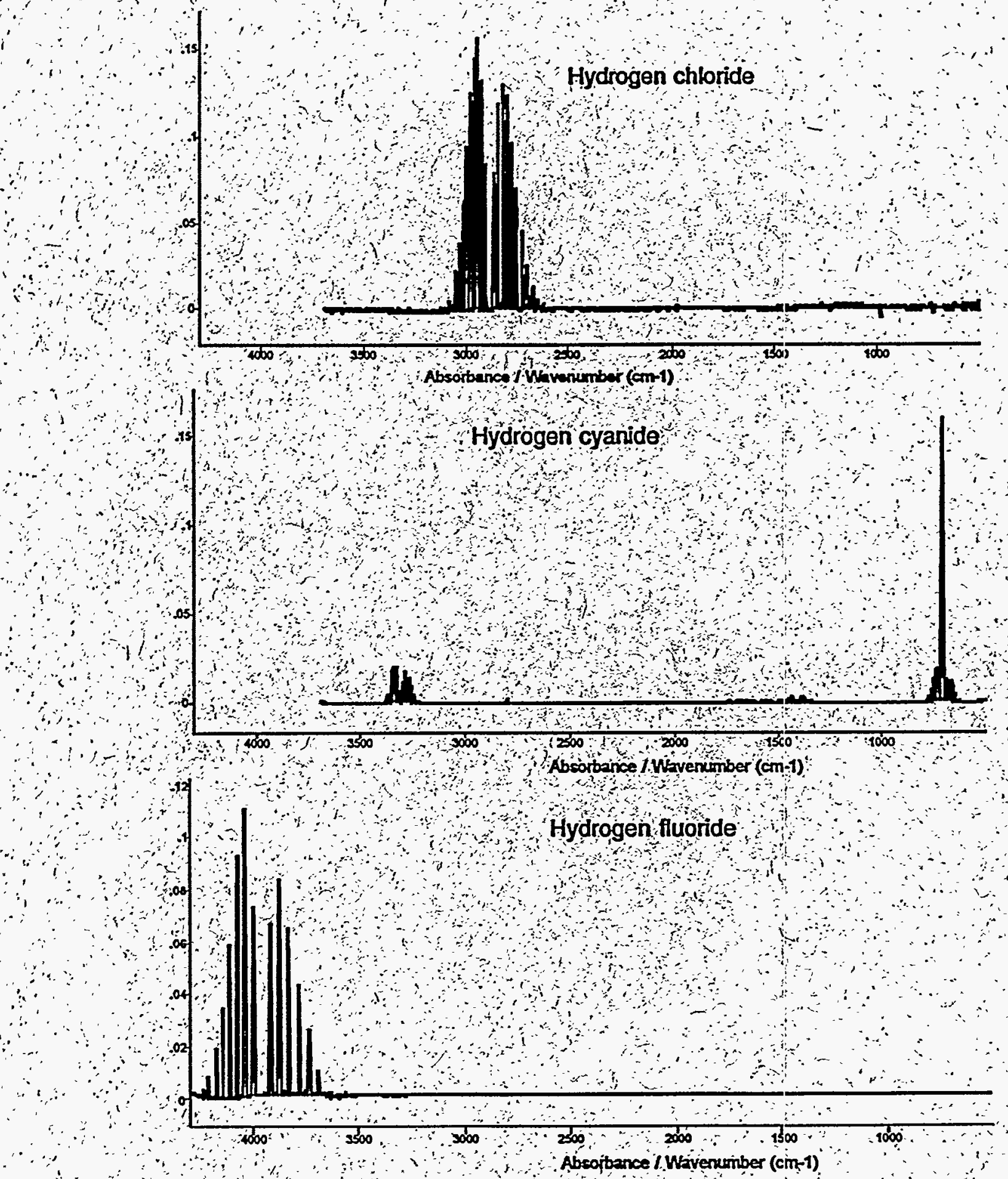

Figure 6 - Spectra of Hydrogen chloride $(285)$, Hydrogen cyanide (36), and Hydrogen fluoride (30). 


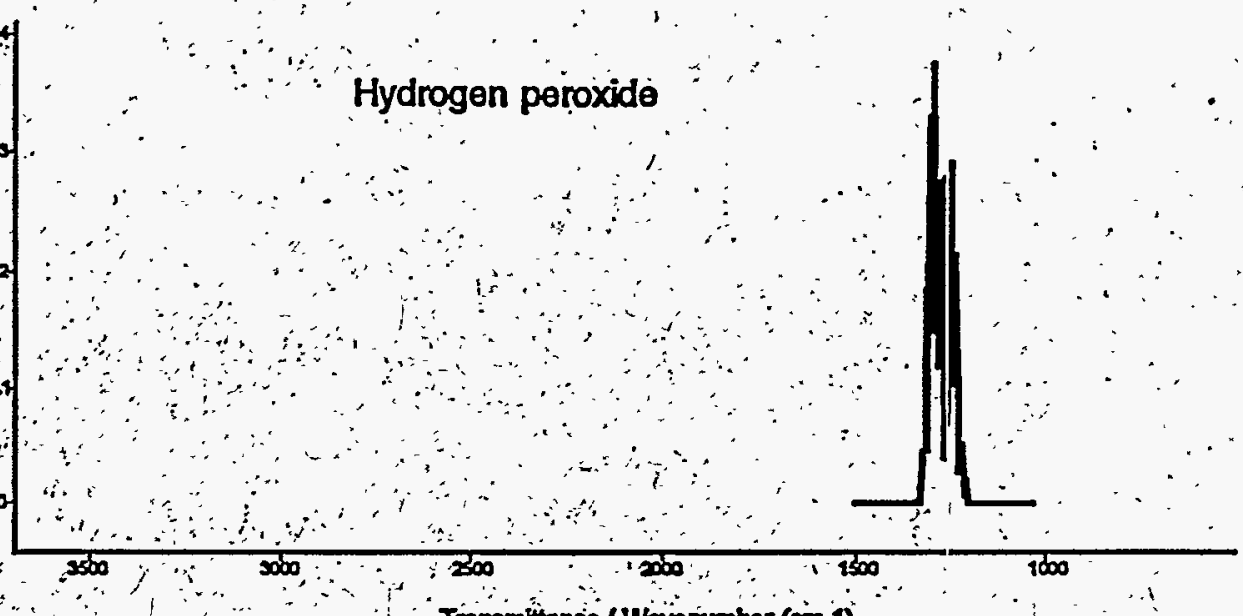

Transmîtenco / Wenvinumber (com-1)

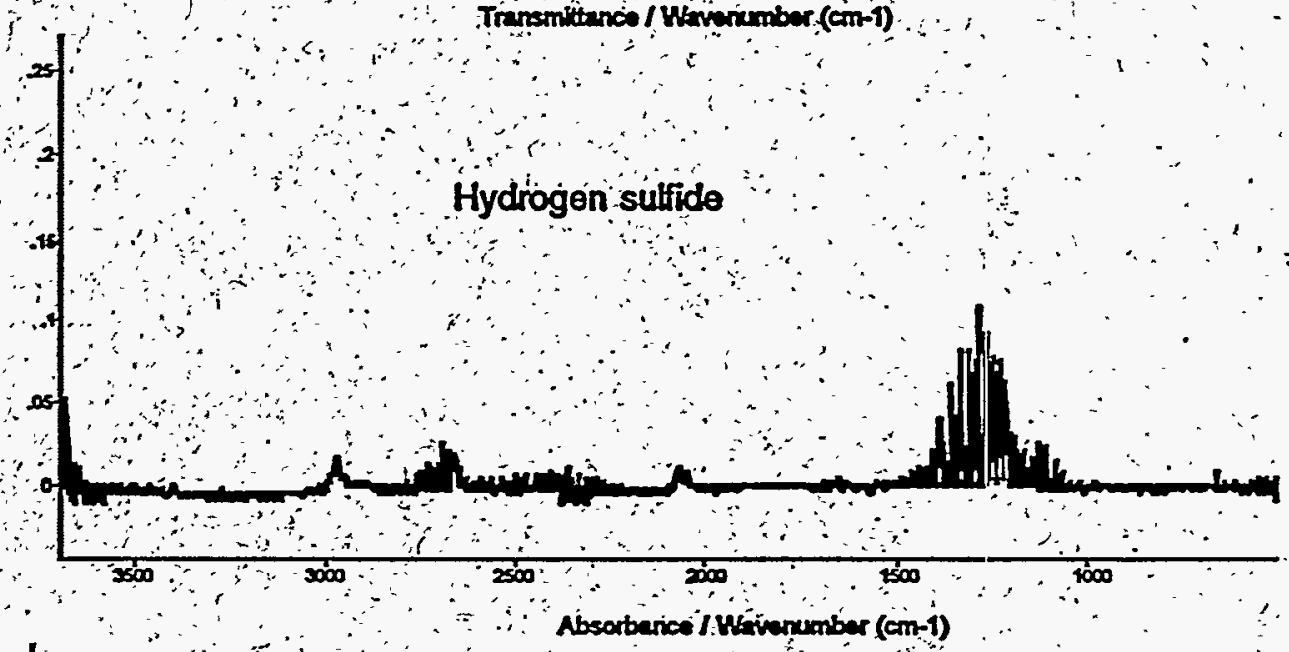

$\because \because$

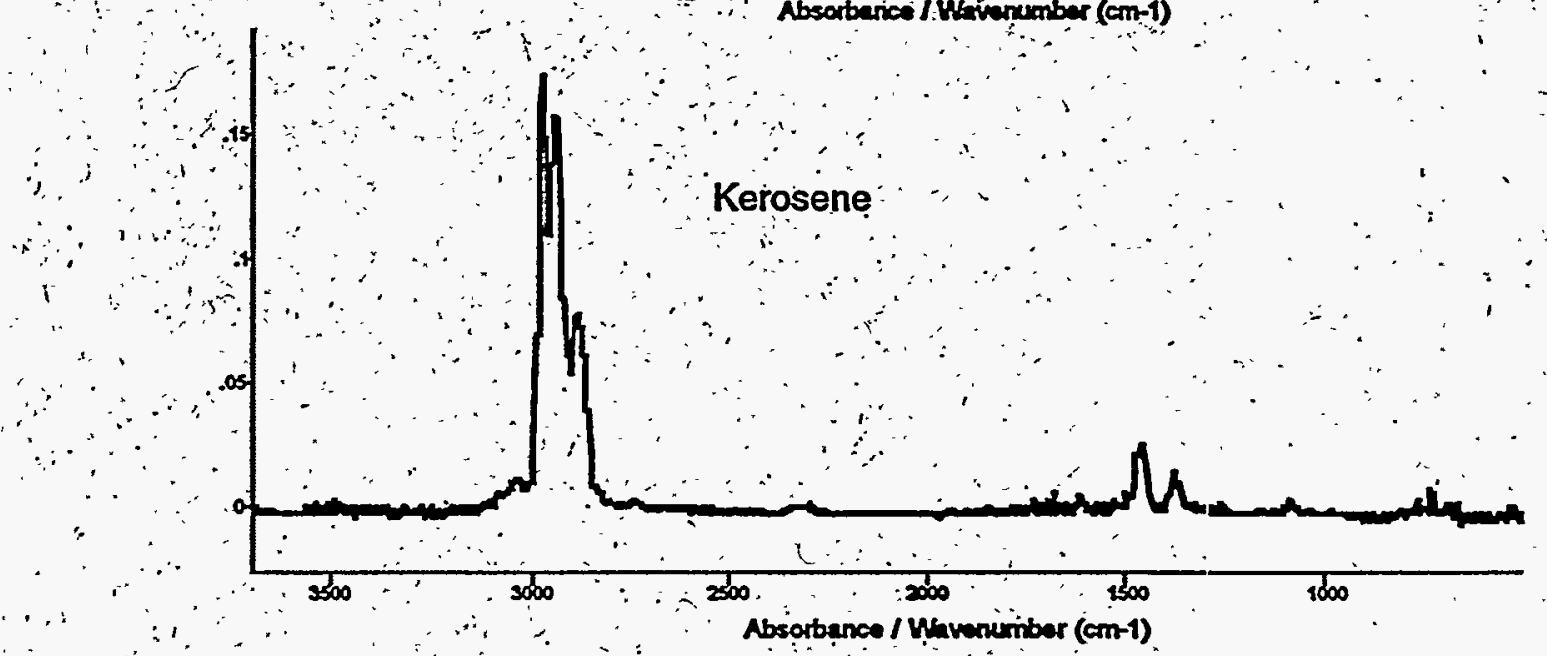

Figure 7 - Spectra Hydrogen peroxide (1000), Hydrogen sulfide (32000), and Kerosene (200). 

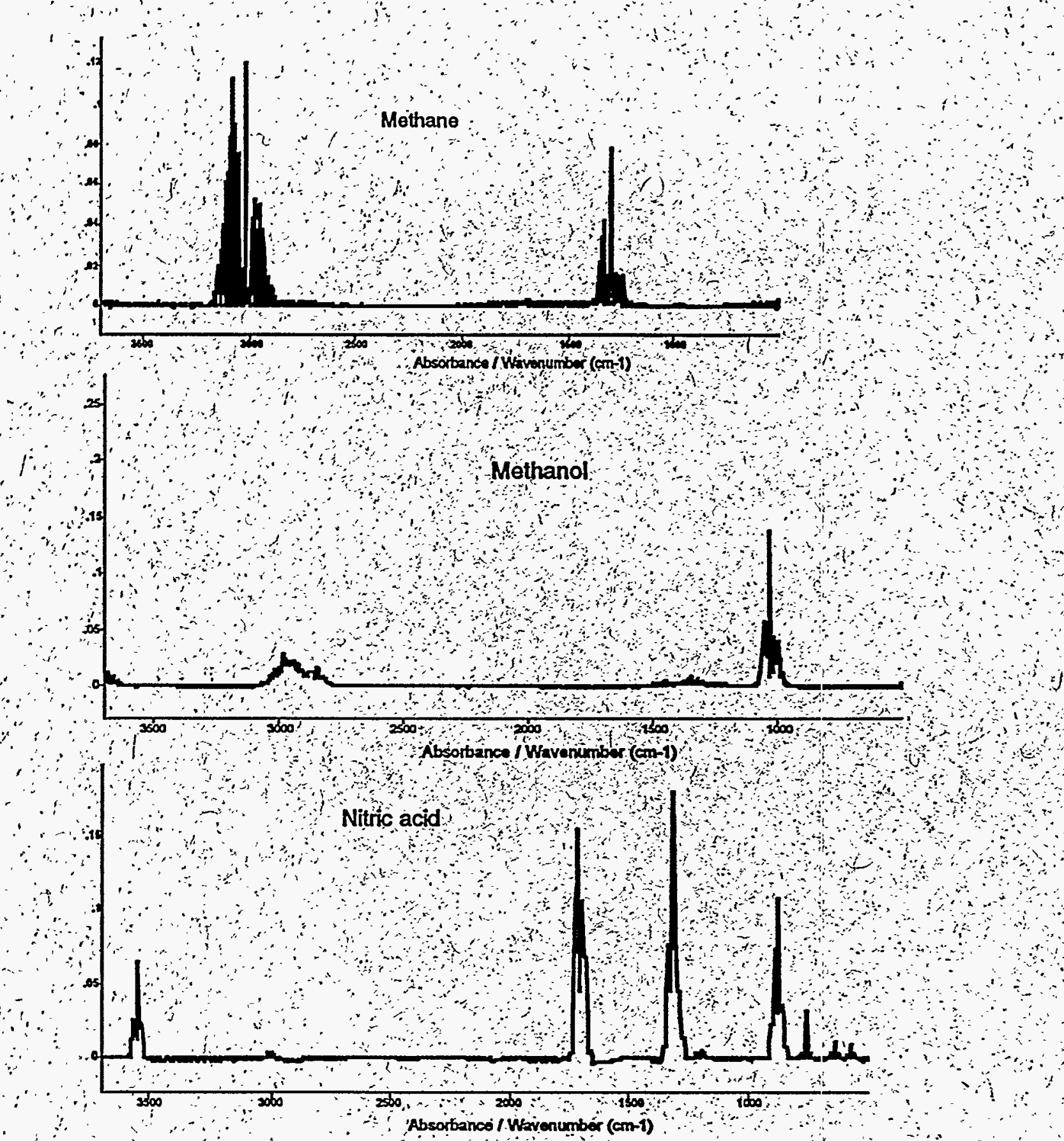

Figure 8 - Spectra of Methane (128), Methanbl (141), and Nitric Acid (140). 

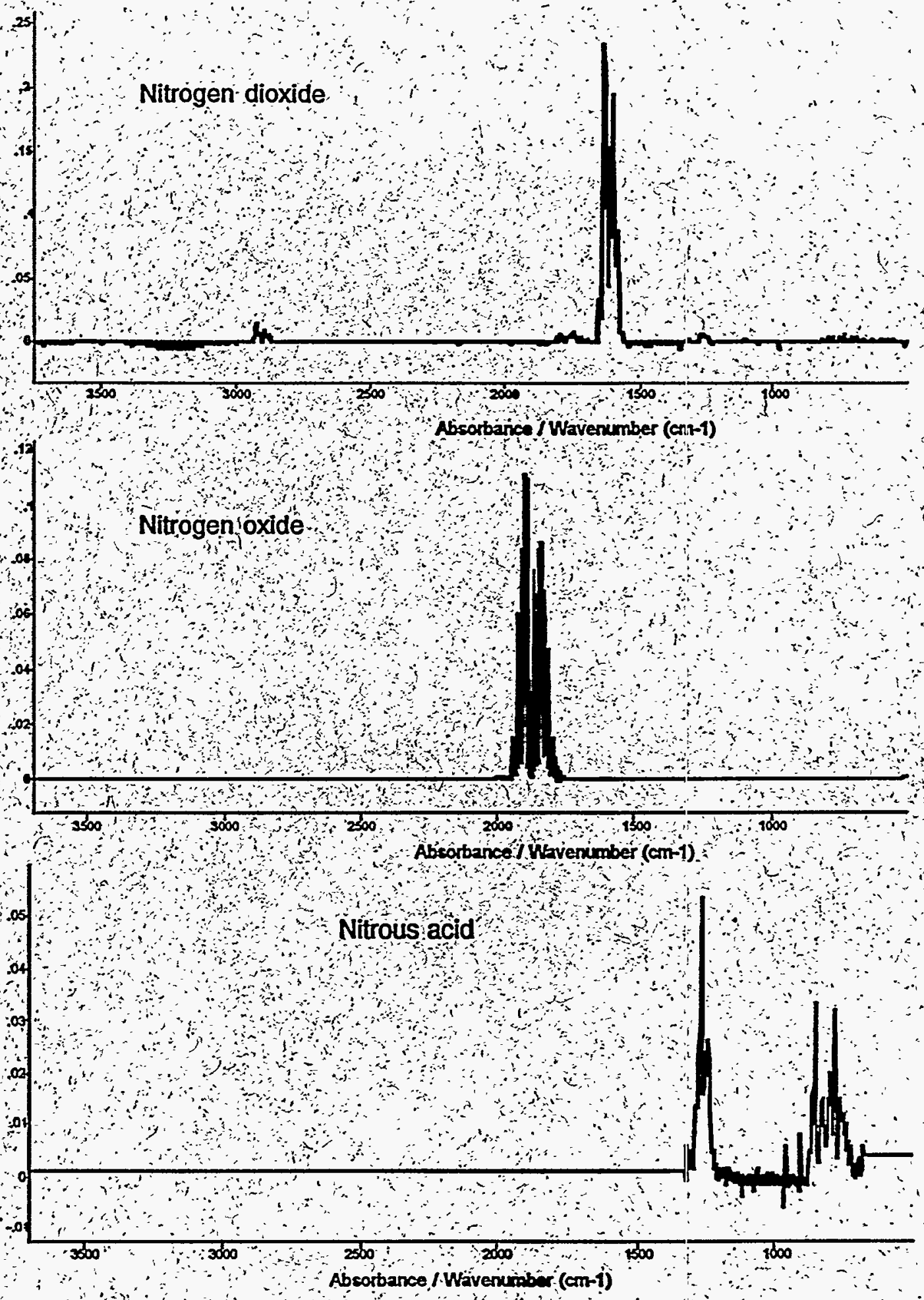

Figure $9-$ Spectra of Nitrogen dioxide (125); Nitrogen oxide (6.25), and Nitrous acid (10). 

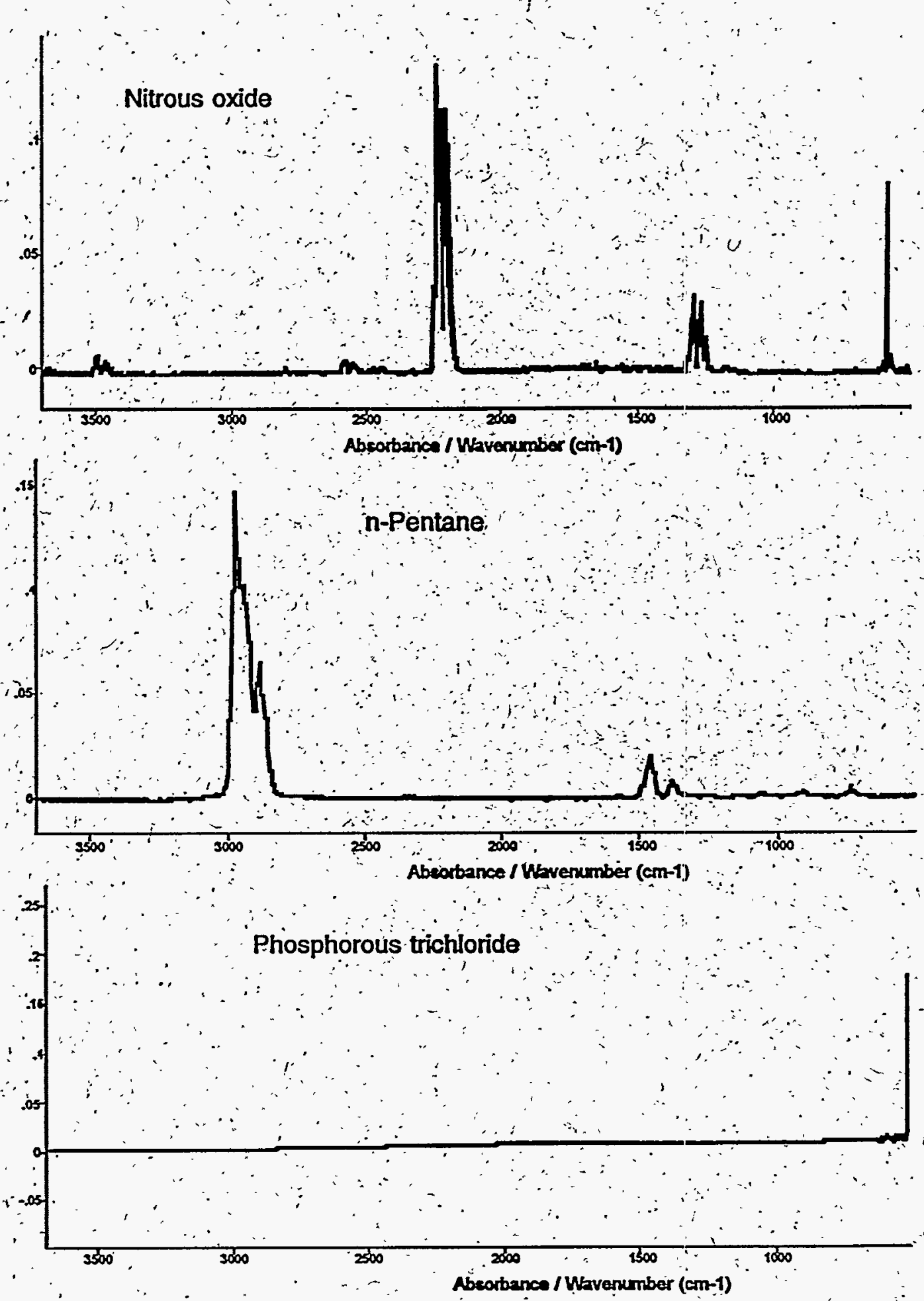

Figure 10 - Spectra of Nitrous oxide (80), n-Pentane (152), and Phosphorous trichloride (700). 

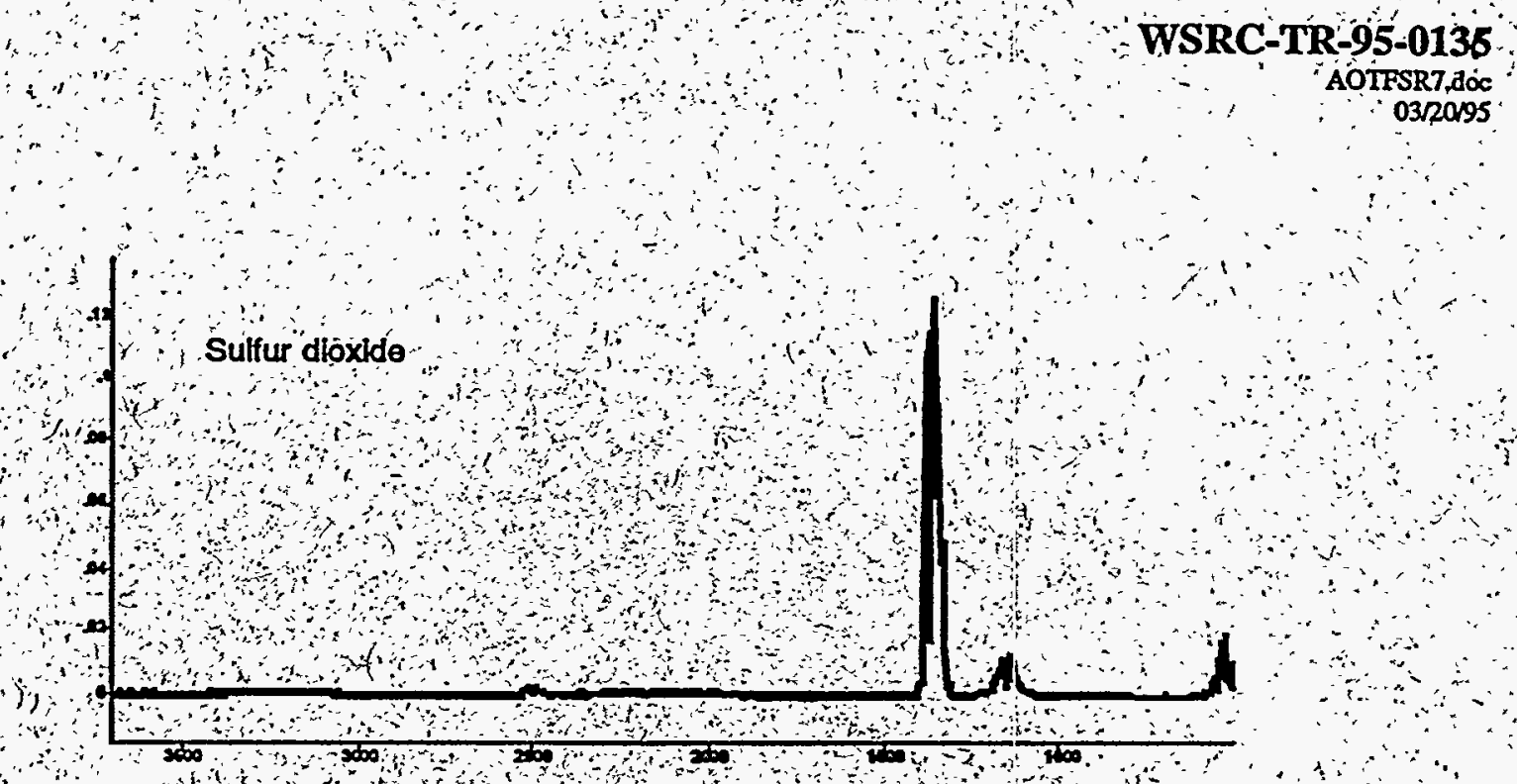





Figure 11 - Spectra of Sulfur dioxide (125), Toluene (137), and Trichloroethylene (160): 

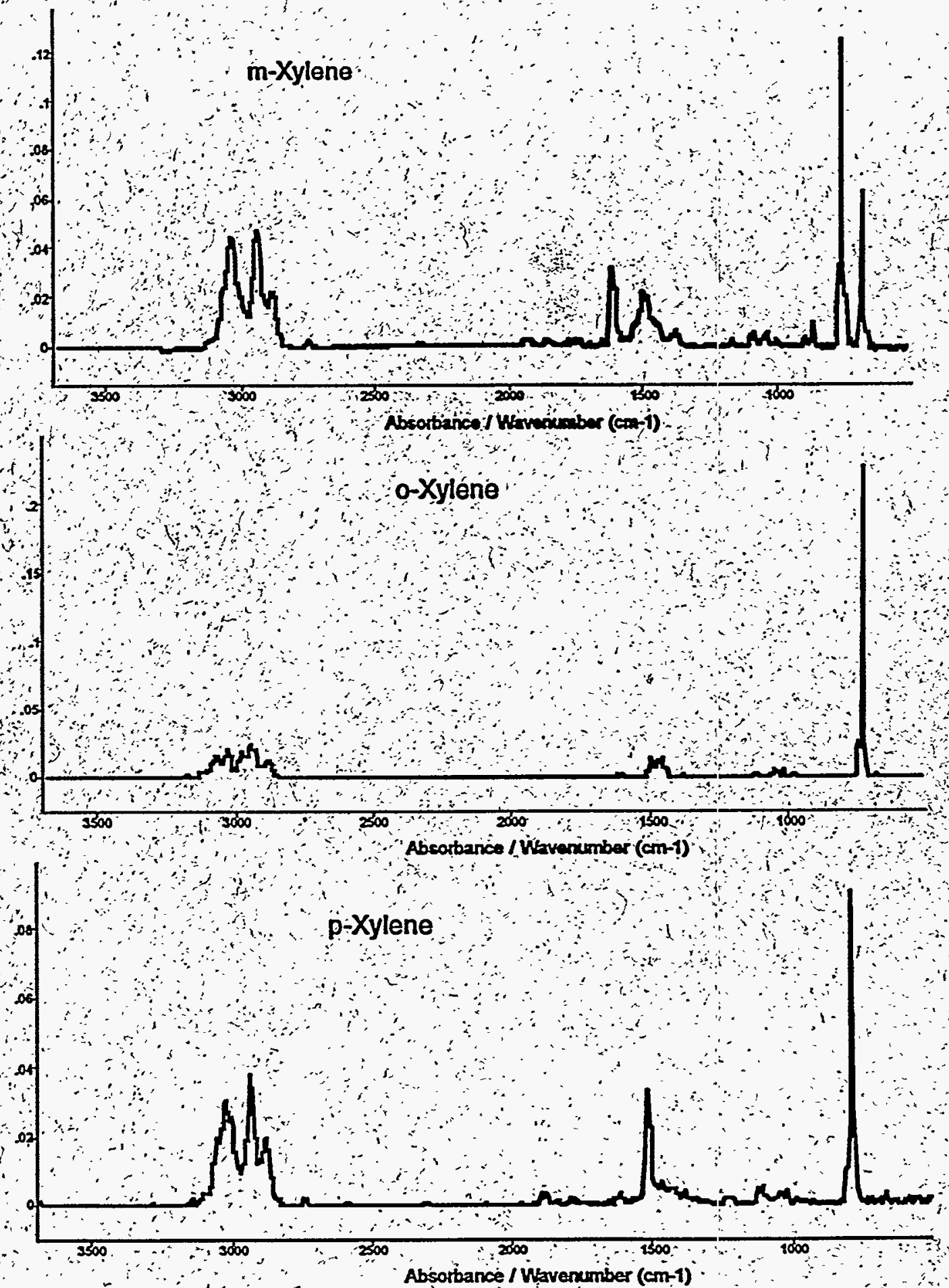

Figure 12 - Spectra of mXylene (200); o-Xylene (100), and p-Xylene (200). 
These spectra, exhibit the major correlations with molecular stricture which are generally useful for distinguishing different classes of molecules. Table 6 lists the major spectra-structure correlations for the 2.38 to $20 \mu \mathrm{m}$ spectral region 16

Table 6. Major spectra-structure correlations are useful for détermining classes of molecules.

Wavenumbers ( $\left.\mathrm{cm}^{-1}\right)$

$4220-3680$

$3700-3100$

$3100-3000$

$3100-2400$

$3000-2700$

$2600-2100$

$2300-1900$

$2000-1700$

$1900-1550$

$1700-1550$

$1660-1500$

$1660-1450$

$1620-1420$

$1500-1250$

$1470-1310$

$1400-1000$

$1350=1150$

$1350-1120$

$1300-1140$

$1300=1000$

$1100 \div 830$

$1000-600$

$900-700$

$830-500$

\section{Molecular Structure}

HF

$\mathrm{OH} \mathrm{NH}$, and $\mathrm{CH}$

Aryl, olefinic, and three membered ring $\mathrm{CH}$

Acidic and strongly bonded hydrogens

Aliphatic $\mathrm{CH}$

SH, BH, PH, and SiH

$X Y$ and $X Y Z$

Aryl and olefinic overtones

CO

$\mathrm{CC}$ and $\mathrm{CN}$

$\mathrm{NH}_{2} \mathrm{NH}_{3}^{+}$, and $\mathrm{CNH}$

NO

Aromatic and heteroaromatic rings

$\mathrm{CH}_{3}$ and $\mathrm{CH}_{2}$

$\mathrm{B}-\mathrm{O}, \mathrm{B}-\mathrm{N}, \mathrm{NC}_{3}^{-}, \mathrm{CO}_{3}^{2-}$, and $\mathrm{NH}_{4}^{+}$

$\mathrm{SO}_{2}, \mathrm{SO}_{3}, \mathrm{SO}_{2}$ and $\mathrm{SO}_{4}$

$\mathrm{CH}_{2}$ and $\mathrm{CH}$ wag

$\mathrm{CF}_{3}$ and $\mathrm{CF}_{2}$

3

\&

$$
P=0
$$

C-O

Si-O and $P-O$

Olefinic $\mathrm{CH}$ wag

Aromatic CH wag

$\mathrm{CCl}_{1} \mathrm{CBr}$, and $\mathrm{CI}$ 


\subsubsection{Source Gas Spectra Measuired for this Program}

To obtain the spectra of eight gases of interest which are not in the Digitized Reference Library, $P$. Hanst of Infrared Analysis, Inc, obtained the gases and performed FIIR measurements with $0.5 \mathrm{~cm}^{-1}$ resolution ât total pressures of one âtmosphere. The gas spoctra are shown in Figures 13 and 14. His comments on the measurement procedures follow.

Dodecane The yâpor piessure was too 10 w for the standard manorneter pressure measurement in a 10 cm cell Three fi of liquid dodecane was vapodzed into a stream of nitrogen flowing into a $144 \mathrm{~m}$ long cell, with a 100 i volume, until one atmosphere pressure was obtained

Nitrogen tetroxide. This dimer only exists in equilibrium with the nitrogen dioxide monomer. The Digitized Reference $\mathrm{I}$ brary $\mathrm{NO}_{2}$ spectrum was subtracted from the measured spectrum to obtain the $\mathrm{N}_{2} \mathrm{O}_{4}$ spectrum

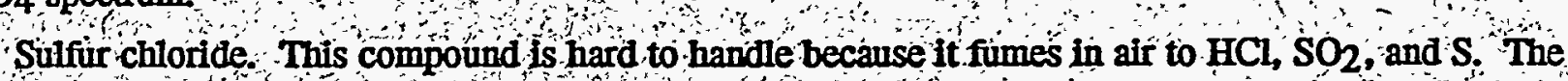
pure compound was quickly transferred to an evacuatable glass bulb frozen in liquid nitrogen and the air pumped off The sample was the wamed and the vapor fowed into a $10 \mathrm{~cm}$ cell HC and SO 2 vapors were mixed with the sulfur chloride and dimensioned by their distiliation concentration The HCl and $\mathrm{SO}_{2}$ bands from the Digitized Reference Library were subtracted from the measured spectrum to obtain the $\mathbf{S}_{2} \mathrm{Cl}_{2}$ spectrum

Thionyl chloride This compound also fumed in air and was handled in the same manner as sulfur chloride After distiliation, a clean spectrim was obtained

Tributyl Phosphate. This compound produced so little vapor that the liquid had to be placed in a glass U-tube closely attached to the 144 mong cell and then unilike for dodecane, heated while nituogen was flowing over it and into the cell The $50 \mathrm{ppm}$ - value was estimated by compang the size of the $\mathrm{CH}$ band at $2900 \mathrm{~cm}-1$ with the size of the $C-H$ bard in the Digitized Reference L L brary spectrum of hutanol. It was assumed that the tributyil phosphate with its three butoxy groups should have a C-H band three times as strong as the C-H band in n-butanol: 
WSRC-TR-95-0136

AOTFSR7.doc:

0320095
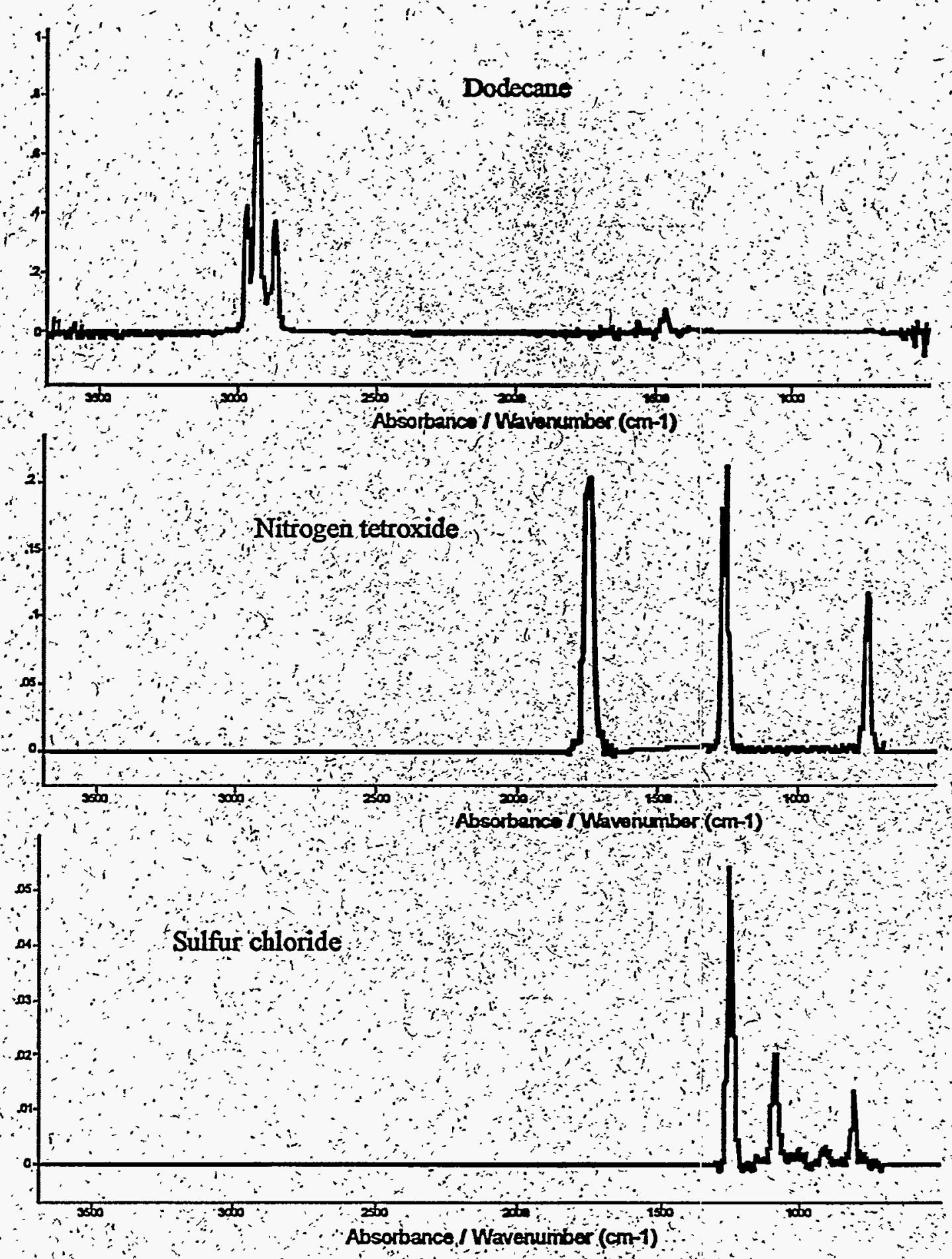

Figure 13 - Measured spectra of Dodecane (310), Nitrogen tetroxide (120), and Sulfur chloride (370). 

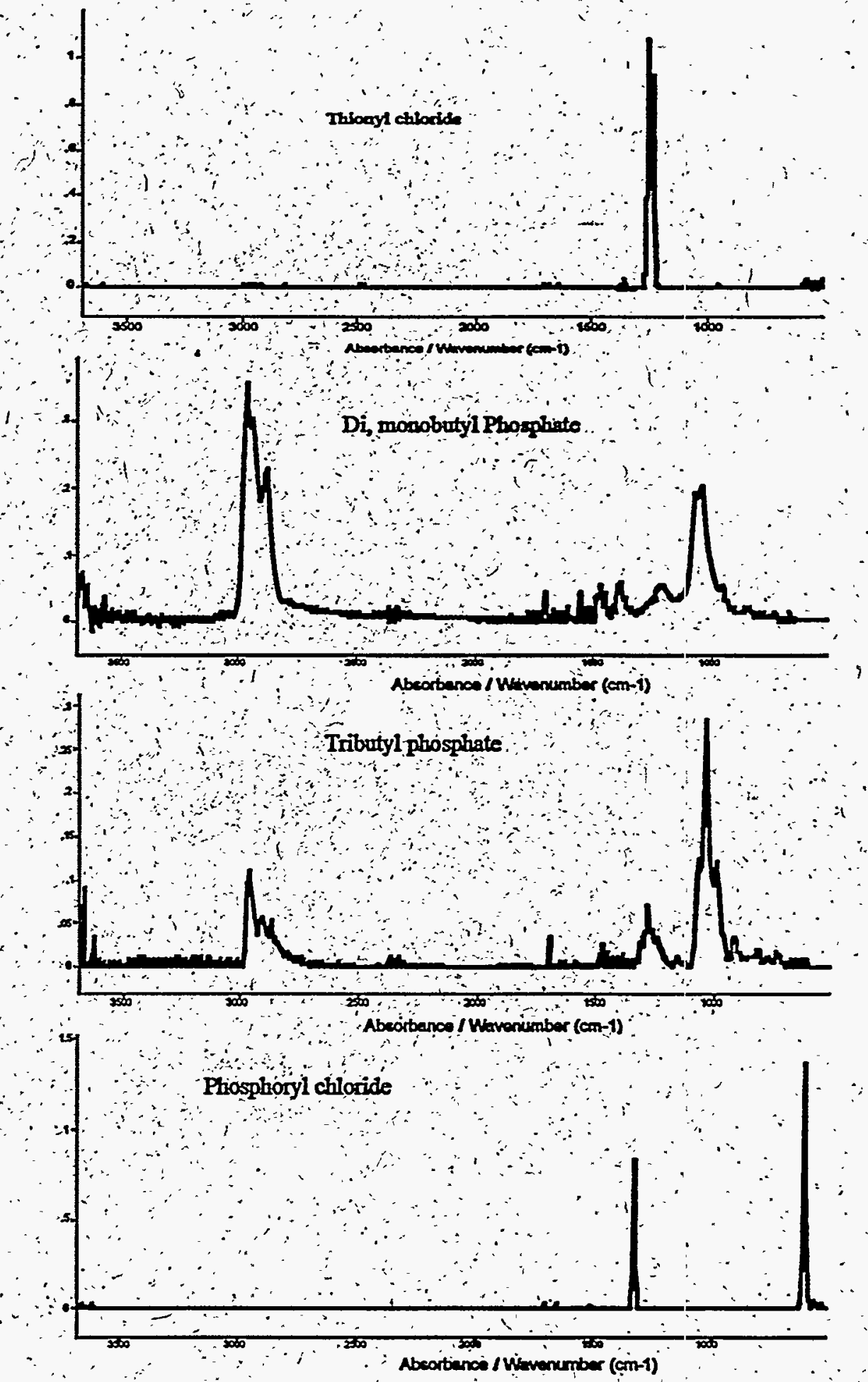

Figure 14 - Measured spectra of Thionyl chloride (770), $55 \%$ dibintyl Phosphate $+45 \%$ monobutyl Phosphate (500), tributyl Phosphate (50); and Phosphoryl chioride (160). 
Dibutyl and monobutyl Phosphates. We were unable to obtain pure samples of these compounds separately but had to use $55 \%$ dibutyl phosphate mixed with $45 \%$ monobutyl phosphate: The vapor pressure was obtained in the same manner as for tributyl phosphate and the $500 \mathrm{ppm}-\mathrm{m}$ value also obtained in the sáme manner.

piosphoryl chloride. Fưming in air was a problem but the vapor pressure was high enough for measurements in a 10 cm cell with the subtraction of some impurity barids.

With these measurements of eight source gases and the thity-one in the Digitized Reference Library plus the atmospheric gas spectra in the same libray, forty two digitized spectra are avaliable for analysis.

\subsection{SPECTRATLINES}

In detecting a source gas and measuring its concentration two genieral features must be considered: the absorbance of the source gas and the absarbance of nonnal atmospheric gases at the same wavelength For the best results, the absorbance of the source gas should be high and the absorbance of the atmosphetic gases should be tow To satisfy the former criterion only spectra peaks of source gases are considered and to satisfy the latter criterion, only spectra peaks of source gases are considered which do not lie within the spectrawidths of any atmospheric gas peaks source gas peaks which satisfy both criteria are called "tag peaks" or "tag lines since they have the highest probability for uniquely identifying the source gas under nomal atmospheric conditions

\subsection{Peak Identification}

The-Lab Calc program automatically identifies peaks in digitized spectra and determines their properties such as peak absorbance width and area several options in the computational methods and print outs are available Described here are the options we selected for the spectra analysis.

The Normal peak picking method, selected for its high accuracy, identifies peaks by a change in the sign of the second derivative It rejects ali negative peak values and all peaks with slopes less than an operator-specified minimum slope We set the minimum sope to 0 which minimizes the number of peaks rejected.

Before applying the "Nomaln peak picking method the spectra data is smoothed by averaging every Na data points into a single value, without modifying the spectruin thace which is rominally composed of 10,000 data points or more This smoothing eliminates most noise spikes but the $\mathrm{Na}_{\mathrm{a}}$ value, which must be an odd number, should be low so as not to eliminate real peaks. We smoothed with $\mathrm{N}_{\mathrm{a}} \doteq 3$

The sensitivity rejection parameter sets the noise level for identifying peaks in a trace A setisitivity level of $5 \%$ specifies that $5 \%$ of all local maxima in the trace are greater than the noise and 
are therefore real peaks. We selected a sensitivity level of $100 \%$ which specified that all peaks identified by the "Normal" peak picking method should be considered as real peaks.

The threshold rejection parameter sets the minimum height for peaks to be included in the Peaks Table. We set the absarbance threshold at 0.0001 , which is $0.1 \%$ of the highest absorbance in the digitized spectra This parameter eliminates small amplitude noise spikes as well as very weak lines: An example trace showing the peak-identifications with a theshold value of 0.1 s shown in Figure 15. In this example, there are only two peaks, Peak 1 and Peal 2 , with values above the threshold value.

Peak edges are initially set where the absolute value of the slope on either side of an identified peak is greater or equal to the specifed ininimum slope The minimum slope value of 0 we selected maximizes the pear widths However, shoulder peals peals that are overtapped on the front of the tail of a larger peak, require special'care In the Normat peak picking method the peak edge locations of shoulder peak are refined by finding a line that is tangent to the trace on both sides of the Identified peak The peak edges are defined by where the tangent line touches the trace. Figure 15 contains examples of peal edges and base lines drawn for an isolated peak peak , and for a pak. Peák 2 having a shoulder peak modifying its peak edges

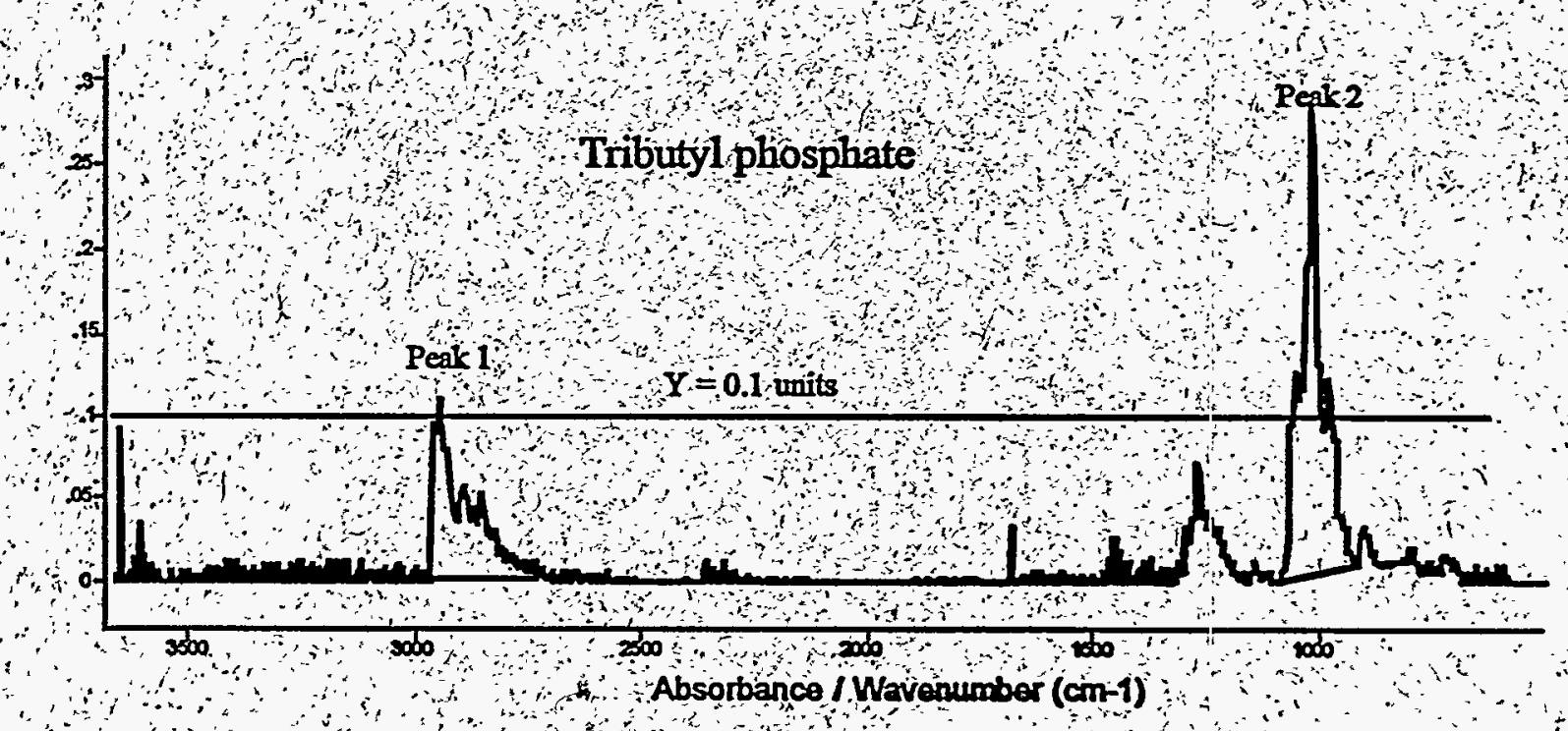

Figure $15-$ Only peaks above the threshold value $(\rightarrow$ are identified. The vertical tick marks denote the edges of the identified peaks and each solia line connecting the trace between the peak edges is the base-line. 
Peak areas are calculated between the peak edges by the trapecioldal rule for integration. An area reject parameter rejects all areas below the operator-specified value. We set the parameter to 0 so as to include all peaks.

'Peak areas' are normally calculated from the trace height above the base line. However, the valleys between peaks do not always drop back to the odiginal base line. In this case, the calculated area will be in emor. To more accurately determine the area peaks lying close to each other can be grouped together and the base line defined by a common bose line that extends from the beginning edge of the first peak to the ending edge of the last peak The areas of the grouped peaks are calculated by dropping vertical lines from the peak edges down to the group base line. This refinement is lllustrated in Figure 16.
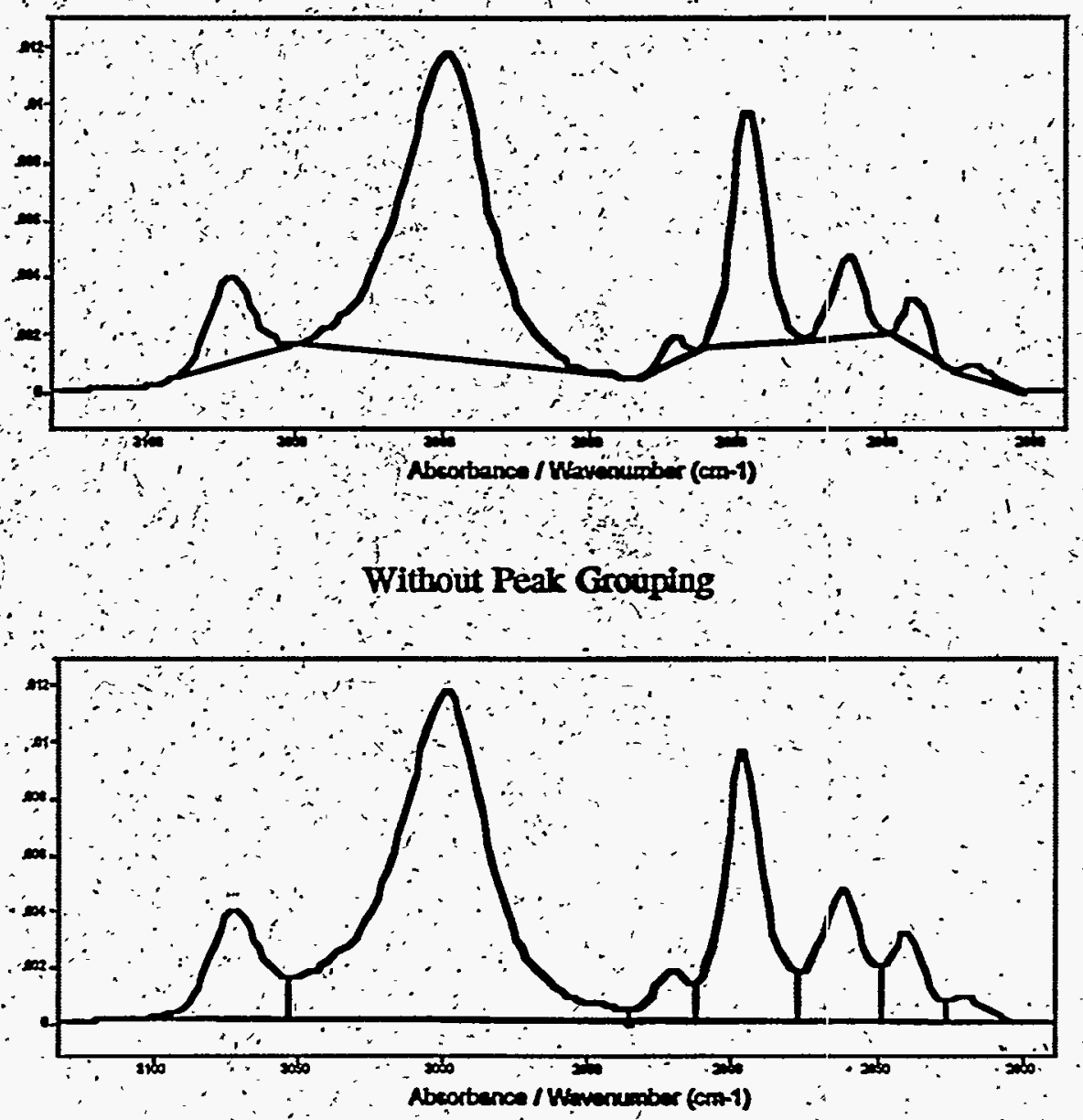

With Peak Grouping

Figure 16 - To determine áccurate areas, close-lying peaks must be grouped together and a common base line determined. The areas determined with and wlithout peak grouping are obviously different. 
To specify, which peaks should be grouped together, a maximium group peak separation parameter is used. Twice the larger half-width of each identifiod peak is compred to the larger half-width of the adjacent peak The peak separation parameter specifies a percentage of the smaller of these two -values. If the adjacent edges of the two peaks are separated by less than this value, the two constitute a group and are given a common base line, We used $100 \%$ Thus if two peaks had maximum halfwidth of $1 \mathrm{~cm}^{-1}$ and $1.5 \mathrm{~cm}-1$, espectively, the y would be grouped together if their adjacent edges were closer than $2 \mathrm{~cm}^{-1}$

The area calculation must also be modified for shoulder peaks if a large peak has a long tail with a much smaller peak iding on top of it, most of the area under the trace belongs to the lage peak Shoulder peaks are identified by three criteria: (1) the dhoulderiand large peak must be with the same group of peaks (2) a shoulde peak must have a significantly highe abo bance at one edge than at the other edge, and (3) the height of the shoulder peak above the common valley with the large peak must be much smaller than the height of the large peak above the same valley. In the thitd criteria, how much smaller specified by the shoulder ratio setting which we set at $33 \%$ This setting specifeed that the heights of shoulder peaks must be less than $33 \%$ of the pear absorbance of the large pear

The areas of shoulder peaks are calculated by drawing a shimmod base line from the beginning edge to the ending edge of the shoulder peak we selected the defaut exponential baseline The remaining area between the shoulder peak baseline and the goup base line is considered to be pait of the large peak This base line modification or shoulder peaks in iliustrated in figure, 17

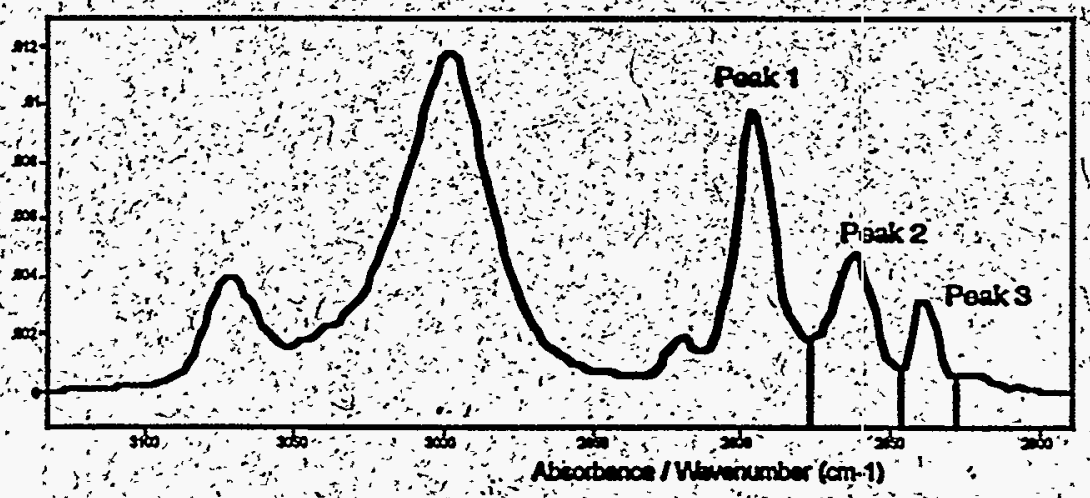

Withoùt Base L ine Modification

${ }^{2}$ Lines are often not symmetrical, which means that the two half-widtis measured from peak center are not the same: 


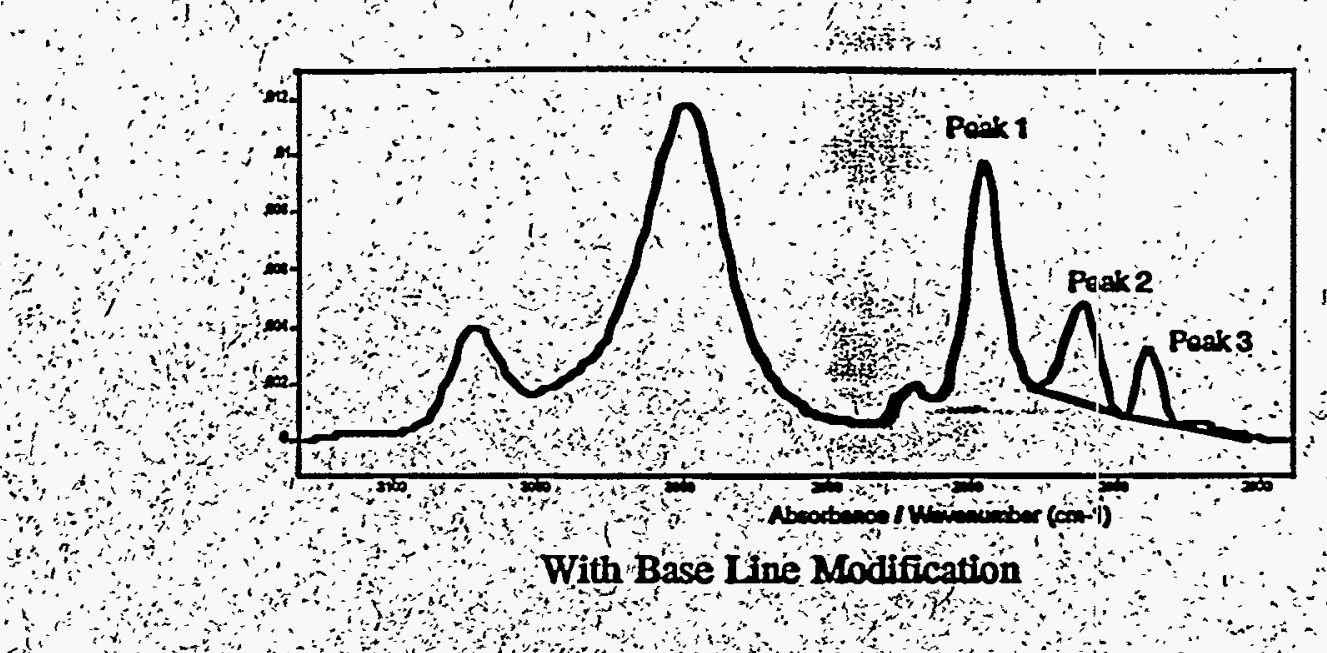

Figure 17 To determine accurate areas of shovider peaks, the dioulder peak must have its base line modified as llustrated The two areas are quite different.

\subsubsection{Peak Tábles}

The peak identification method fust described was applied to al 42 spectra in Figures 1 through 14, ove their entire spectra range the Lab Calc produced Peaks Table for each spectrum was then transformed by the PEAKTB Program into a Modified Peoks Table in which all positive peaks above the threshold level (usually 0.0001 ) and below the maximum level (usually 1.0) are ordered from the highest to the lowest wavelength

Carbon tetrachloride is a good gas to linustrate the different Peaks Tables because it has a simple spectrum, shown in Figure 4 , with only 15 peaks Its vodified Peaks Table is shown in Figure 18 The header lines in the table specify the resolution in cm- 2 nd the interval over which the spectrum was measured The odiginal concentration-path length (cl) valie of the measirements is given as well as the operator specified present value to which the absotonce and area ate scaled. The threshold and maximum absorbance values are given in the final header line for each peak its number, peak absowbance and wavelength are given in the first three columns The next fiye columns describe the extent of the ine: the wave number of (1) the left edge, (2) the peak (called the center). (3) the right edge, and (4) the width of the line The last column gives the area under the line which is a measure of its strength

The PEAKTB Program also produces the Sorted Peaks Table in which peaks in the Modified Peaks Table are sorted to list the peaks from the highest to the lowest peak absoibance The Sorted Peaks Table for carbon tetrachloride is shown in Figure 19 This table is very useful in locating the high absorbance peaks in complicated spectra which have tuindreds of peaks. Note that the Peak Number in the Modified and Sorted Peaks Tables is simply a sequence inimber and not a property of the peak. 


\section{CARBON TETR COTIORIDE}

Resolution: $2 \mathrm{~cm}^{-1}$. The spectrum interval is 388 to 3700 in wavenumbers. The original cL value is 27.0 ppm-m. The minimum absorbance is 0.0001 and the maximum absoibance is 1.0000 .

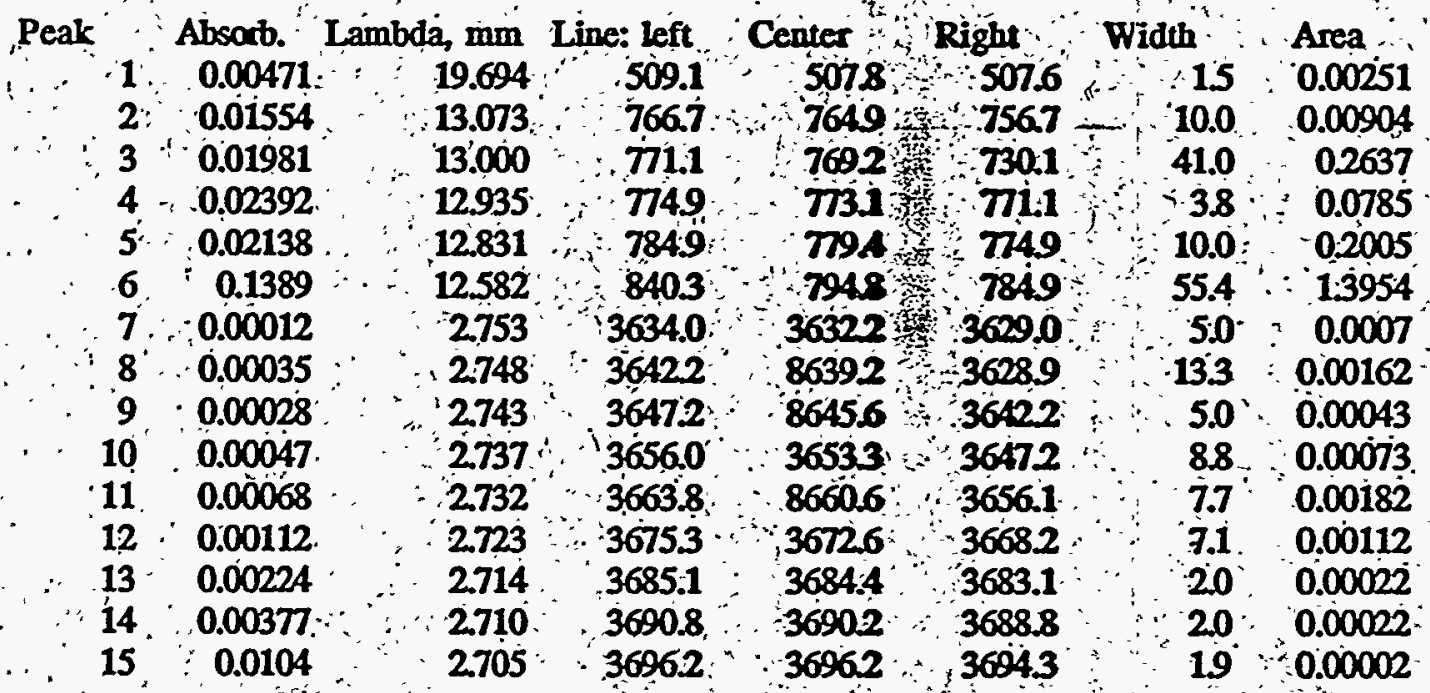

Figure 18 - Modified Peaks Tables give key line information in which the peaks are ordered from the highest to lowest wavelength.

\section{CARBON TETRAC CHIORDE}

Resolution $2 \mathrm{~cm}^{-1}$. The spectrum interval is 388 to 3700 in wavenumbers original cL value is 27.0, ppm-m. The minimum absorbance is 0.0001 and the maximum absorbance is 1.0000 .

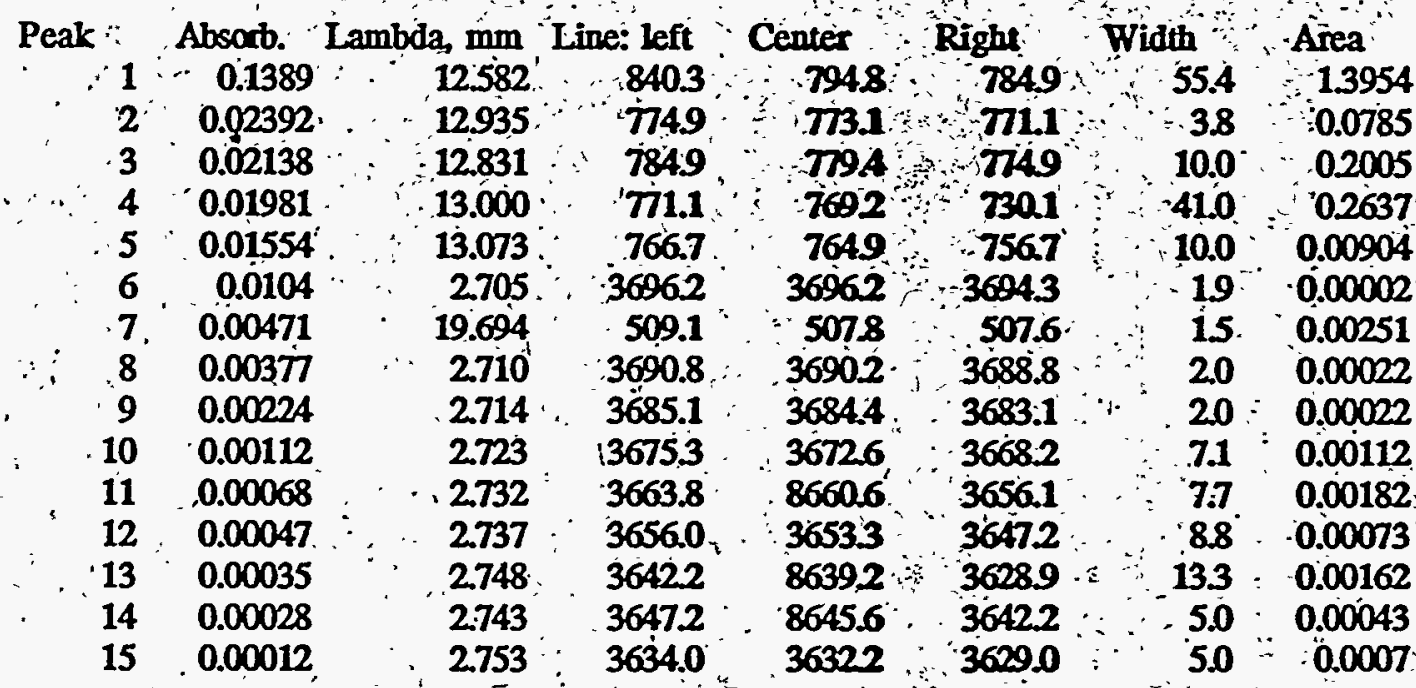

Figure 19 - Sorted Peaks Tables give key line information in which the peaks are ordered from the highest to lowest absorbance. 


\subsubsection{Highest Non-Interfered Peaks}

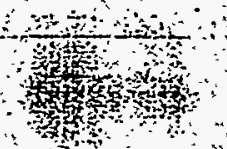

From the Sorted Peaks Tables, the highest absorbance peals are always Peak No. 1. By linearly scaling these highest absorbance peaks to the same concentration, say 1000 ppm-m, the relative detection potentials of the gases are obtained Table 7 list these peaks for the gases of interest as well as for the atmospheric gases The absorbance and wavelength at the peak center is given for each gas, as is the total number of peaks, or lines, detected from the digitived spizctra for peak absorbances above

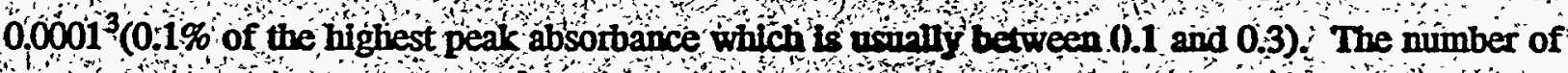
peaks in a spectrum is a wough measure of the spectrum complexity - the 41 spectra produced 7,904 peaks This table is important because it indicotes the onotive detection probabilities and gives the best Wavelengths for accurate measurements of gas concentrations when the atmosphere is not impoitant, 1 , when the monitor is close to the plume

When the plume is at a distance atmospheric absoption must be considered This effect is negated for each gas of interest by compang its Sorted Peak Table to the Modified Peaks Table for each atmosphér gas listed Th Table $3, \mathrm{C}_{2} \mathrm{H}_{2} \mathrm{CO}_{2}, \mathrm{CH}_{4}, \mathrm{~N}_{2} \mathrm{O}$ ani $\mathrm{CO}$ For each gas, the highest absorbance line which does not oyerlap an amosphetic line is taken as the tag peak ie., the line which is uniquely ldentifies the gas, To be a tag line we specified that the line could not lie anywhere within the widt of any peak the atmospheric gas apecto This stringent requirement does. not guarantee the selection of a high absotonce tag line but it has a high probability of eliminating atmospheric interferences leaving on the less troublesome continum absorption

The tag lines are listed in Table 8 in order of absabance values Tag lines which would be detected with a far-infrared focal plane aray are listed in Table 8 in the normal font and tag lines which would be detected with a mid infrared focal palane array are listed in italics The majority of gases would be identified with the far-infrare amay es HgCdTe, and a few would be identified with the mid-infrared array; e.g. Ins

\footnotetext{
To eliminate noise spikes, this threstiold was slightly higher for most of the gases measured on this program 
WSRC-TR-95-0135 AOTFSR7.doc

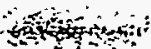
032005

Table 7. Number of peaks and the marimim shorbiance line at 1000 ppm-m for each gas surveyed, assuming no atmospheric effects.

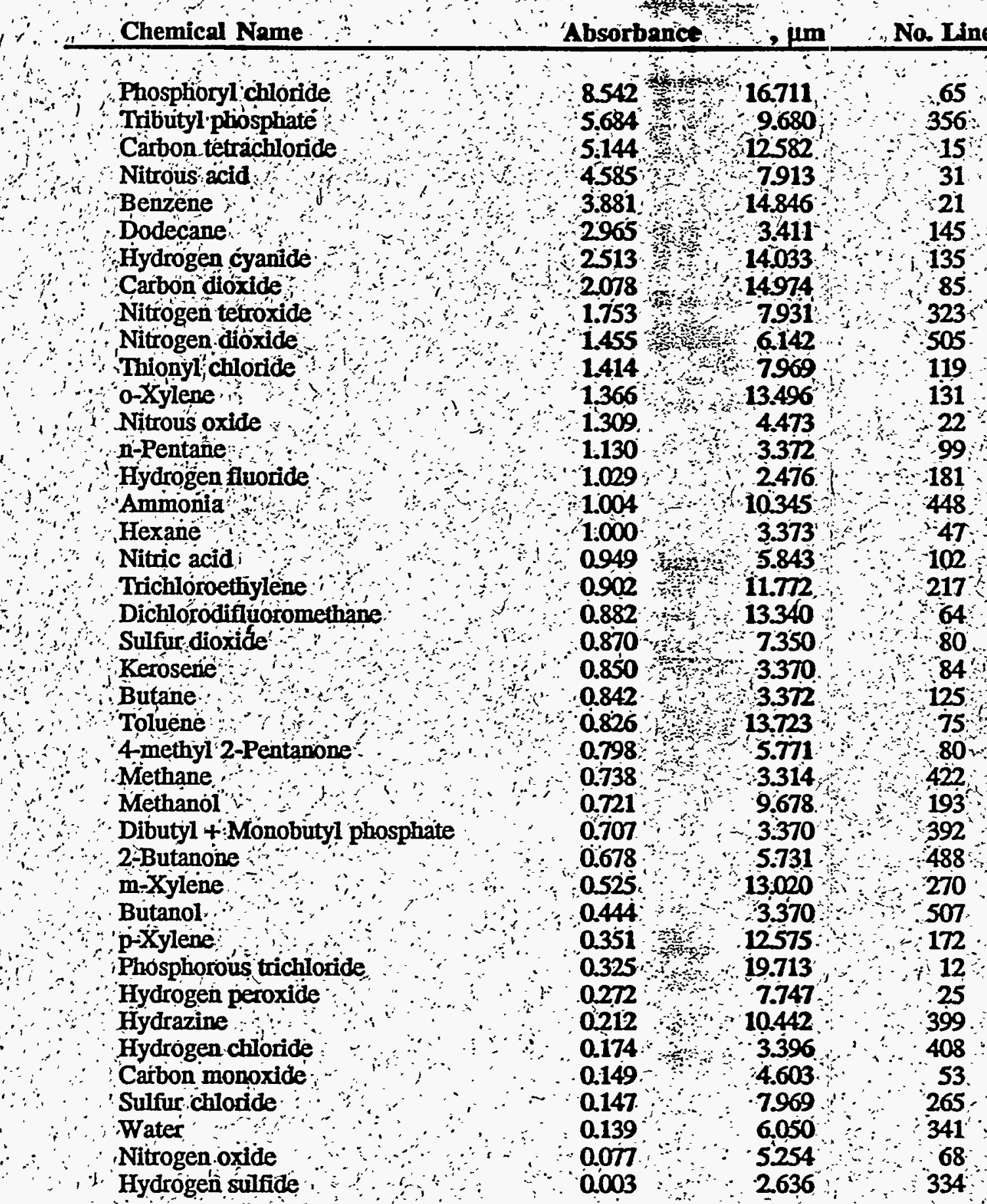


WSRC-TR-95-0136

AOTFSR7.doc

032095

Table 8. Tag line and absorbance properties at $1000 \mathrm{ppm}-\mathrm{m}$ of erch gas for which there are no interfering atmosphéric lines.

Chemical Name

No.

Tributyl phosphate

"Carbon tetrachloride

Nitrous acid

Trichloroethylene

Ammionia.

Dichlorodifluoromethàne

Hydrogen fluoride

Methảne

Methainol

m-Xylene

Nitric acid

Di + Monobutyl phosphate

p-Xylene

2-Bútanone

Hydrogen cyanide

Butanol .

Hydrazine

O-Xylene

Dodecane

Nitrogen tetroxide

4-methil 2-Pentanone

Sulfur dioxide

Benzene

Sulfur chloride

Toluene

Nitrogen dioxide

n-Pentane

Butane

Thionyl chloride

'Hexane

Kerosene

Nitrous oxide

Hydrogen chloride

Nitrogen oxide

Hydrogen sulfide
9.680

12.582

11.731

11.772

10.741

13.092

2.499

3.3.14

9.678

13.020

11:382

9.608

$12: 575$

8.552

2.999

9.349

10.631

3.361

3.514

12.940

8.877

8.597

9.639

9:144

9.692

13.187

10.928

10.455

4.015

8.722

9.166

3.922

3.771

5.131

2.599

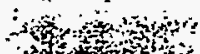

to

Absarbance Width

iim

and
$-1$




The line number in Table 8 indicates the amount of atmospheric interference to that gas. For example, the trichloroethylene tag line is line "1 from the Sorted Peaks Table, i.e, there are no atmospheric interferences for trichloroethylene On thie other hand, the toluene tag line is line $\$ 27$

from the Sorted Peaks Table, ie, atmospheric gases inteffere with the 26 lines with higher absorbances. The line widths give an indication of how large the tag line is.

As seen in Table 8, seven of the gases had no atmospheric interference, Not surprisingly, methane was the main atmospheric interferent due to its very large number of lines from its $\mathrm{C}-\mathrm{H}$ stretch vibrations in the 2.7. 3.8 fm region and other lines in the 5.0 to $8.6 \% \mathrm{~m}$ region The second most prevalent interferent was water with its many vibrational lines in the 2.5 to 3.3 jum region, in the 4.8 to 79 im tegion and in the 15.7 to 19.6 \% region Caron dioxide was the third most prevalent interferent obstructing emissions in the 4.2 to $4.4 \mu \mathrm{m}$ region and in the 13.9 to $19.9 \mu \mathrm{m}$ region In particular, methane interfered with 27 gases of interest, water with 23 gases of interest, and carbon 4 dioxide with 16 gases of interest Nitrous oxide only interfered with 2 gases and carbon monoxide with one.

Three gases have emission lines which are always ovedapped with atmospheric emission lines:

Phosphoryl chloride

Hydrogen peroxide

- Phosphorous trichloride

Their concentrations cannot therefore be unambiguously measured without first removing atmospheric emission lines by carefully and accurately determining their concentrations - a timeconsuming task - and even then the interferences place a lower bound on the measurable concentrations.

\subsection{RELATIVE DETECTION PROBABITITY}

Identification of the tag line for each source gas locates the wavelength which maximizes the probability of detecting low concentrations of that gas in the open atmosphere. The next step is to Identify those gases which have the highest probability of detection relative to the other source gases, thereby providing a rank ordering of the gases according to their probability of detection Such rank ordering is advantageous for AOTF-based spectrometers which measure spectra sequentially because it allows faist searching of an area for tell tale gases by concentrating on the gases with the highest probabilities of detection There are two cases of interest thick plumes and thin plumes, where thick and thin are defined by their optical thickness - Le, optical absarption 


\section{WSRC-TR-95-0135}

AÖTFSR7.doc

032095

\subsubsection{Thick Plume Detection}

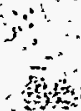

The exact probability of detection for a source gas depends on several factors, such as the gas's. absorbance, temperature, and wavelength, os well as on the receivers collector area and optical transmission. Some factors depend only on the optical desion and will not change appreciably for the different gases. These factors can therefore be npresented by constant $K_{1}$ and the power density on the recelver's detector from gaseous emissions con be written ase

$$
\begin{array}{r}
\mathrm{P}_{\mathrm{I}}=\mathrm{K} \mathbf{P} \\
\mathrm{P}=\mathrm{W}
\end{array}
$$

where is the emissivity at the wavelength, $w$ is the pectral biaciondy emittance in w/cm ${ }^{2}$ ing and is the AOTF passband in $\mu \mathrm{m}$.

$\therefore$ The Planck radiation law provides the w functionality as 1

$$
\mathrm{W}=\mathrm{c}_{1} \mathrm{~s}[\exp (\mathrm{c} 2 \mathrm{~h})-1]
$$

in W/jm cm where $T$ is the blackbody temperature of the gas and

$$
\begin{aligned}
& c_{1}=3.7415 \times 10^{4} \\
& c_{2}=1.4388 \times 10^{4} \\
& w_{\mu m}^{4} \mathrm{wm}^{2}
\end{aligned}
$$

The passband of an AOTF is constant in wavenumbers, not in wavelengths The relationship between them is given by

$$
1042 \Delta v
$$

where is the AOTF passband in $\mathrm{cm}^{-1}$. For an optically thice plume.

$$
\because 10 \quad 4
$$

which reduces Eq. 6 to

$$
\left.P=3.7415 / 3 \exp \left(c_{2} / T\right)=1\right]
$$

for the normalized power density incident on the detector from that fraction of the blackbody radiation from the source gas passed through by the AOTF. 
Values of this normalized power density for 225 C plume gre given in Table 9 for the source gases of interest at their tag line wavelengths. The values are relatively large for the long wavelengths but decrease rapidy for wavelengths below $8 \mathrm{\mu m}$ and almoct fallof of the blackbody radiation curve at the shot wavelength but aided by the lower fractional passband of the AOTF at the shorter wavelengthe if foliow from Eq s that the wavelength at which the normalized power density is peaked is given by

$$
\text { peak }=47961 \mathrm{~T}, \mathrm{~T}<4796
$$

The peak wavelength for a $25 \mathrm{C}$ plume is $16.09 \mu \mathrm{m}$. For the peak wavelength to be even as low as 12 $\mu \mathrm{m}$ the plume temperature would have to be $126 \mathrm{Cl}$. Plume radiance clearly favors far-infrared wavelengths, discriminating strongly against the mid-infrared and near-infrared wavelengths.

Although a high power density from the plume is needed at the detictor, it is not sufficient. The detector noise must also be low to provide ahgh signal-tonoise ratio The noise power at the detector is given by

$$
\begin{aligned}
& P_{n}=\left[A_{d}\right]^{1 / 2} D^{*} \\
& =K_{2} / D^{*}
\end{aligned}
$$$$
\text { Hith }
$$

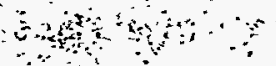

where $A_{d}$ is the area of the detector and fis the electrical noise bandwidth in Hz, collected together in. the design constant $\mathrm{K}_{2}$. The detector detectivity is a function of wavelength and detector material For the far-infrared the most common material is HgCaTe and for the mid-irifrared the most common material for sensitive detection is InSb. Nominal $D^{*}$ values for these detector materials are:

$$
\begin{aligned}
& \mathrm{D}^{*}=\left(2 x^{2} 10^{10}\right) \times 14 \text { HgCaTe } \\
& D^{*}=\left(1 \times 10^{11}\right) M^{5} \text { InSb }
\end{aligned}
$$

where the HgCdTe detector would be used for wavelengths from 5 to 14, $\mu \mathrm{m}$ and the InSb detector for wavelengths from 2 to 5 $\mu \mathrm{m}$. These values are also given in Table 9. The higher sensitivity of the InSb favors the mid-infrared wavelengths.

A relative merit factor is obtained by eliminating the system desigin details which have little, if any, dependence on the wavelength and including those remaining parameters which determine the signal-to-noise ratio, i.e..

$$
\mathrm{MF}_{1}=10^{5} \mathrm{PD}^{*},
$$




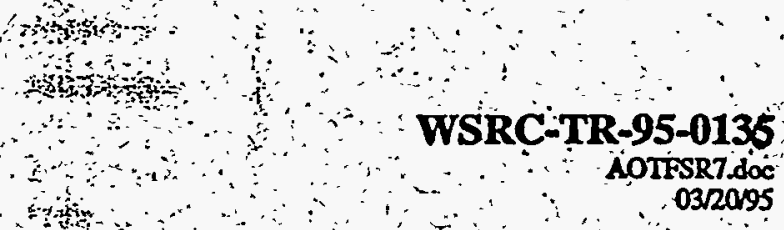

where the 105 factor scales the merit factor to values near unity. Values of this mexit factor for the source gases of interest are given in Table 9: This merit factorindicaters that it would be $10^{6}$ times more difficult to detect a thick plume of dodecane than a thick plume of carbon tetrachloride or $p$ xylene, etc; ' It readily apparent that the higher sensitivity of Insb detectors does not compensate adequately for the rapid decrease of the blackbody rodiance it the shot wavelengths Thus the farinfrared wavelengthis are yery useful for the detection of cource gases in thick plumes whereas the midinfrared wavelengths' are not.

WSRC-TR-95-0135

AOTFSR7doc' "0320195

Table 9. Detectivity merit factor for an optionlly thick gas plume at $25 \mathrm{C}$

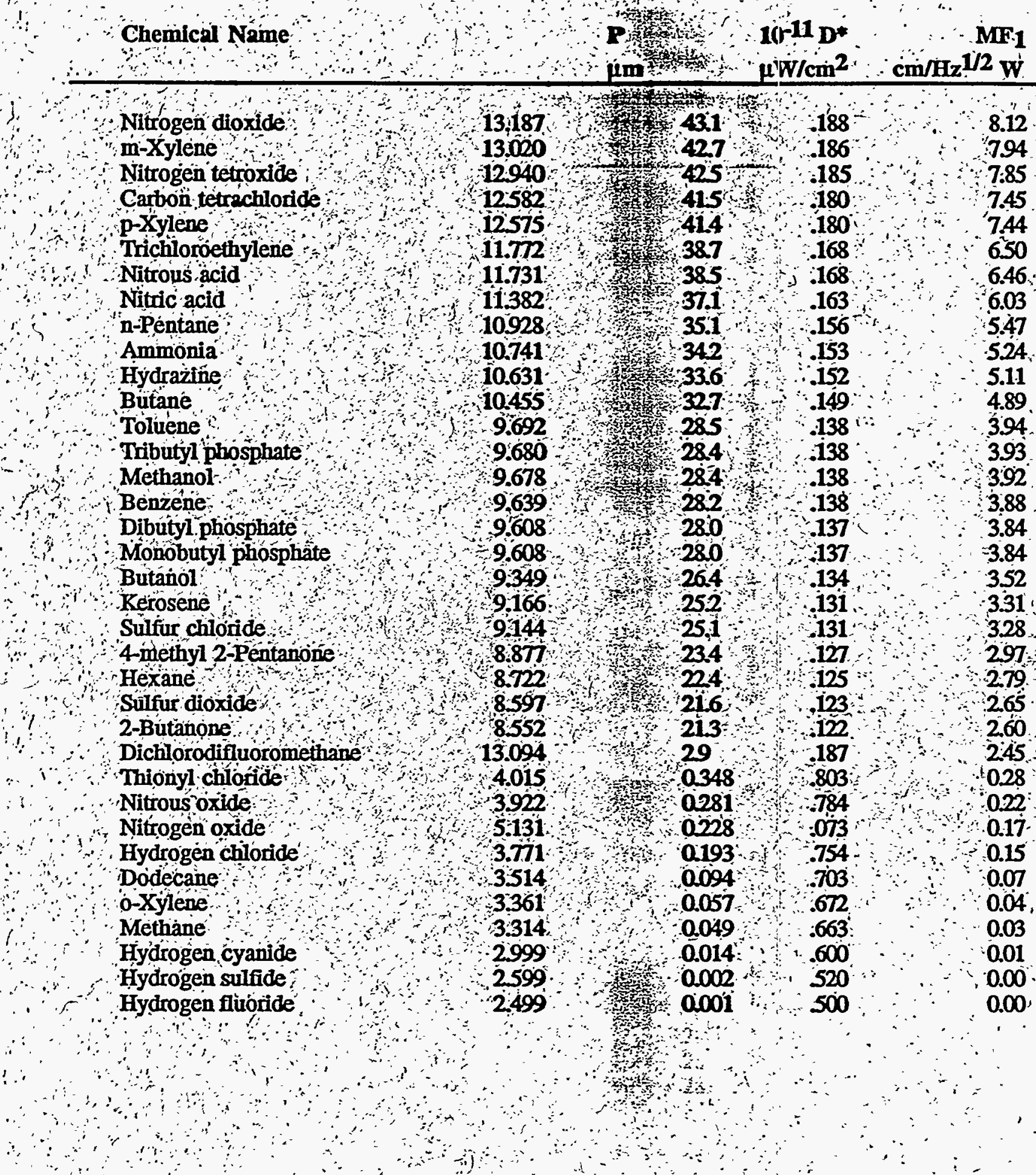




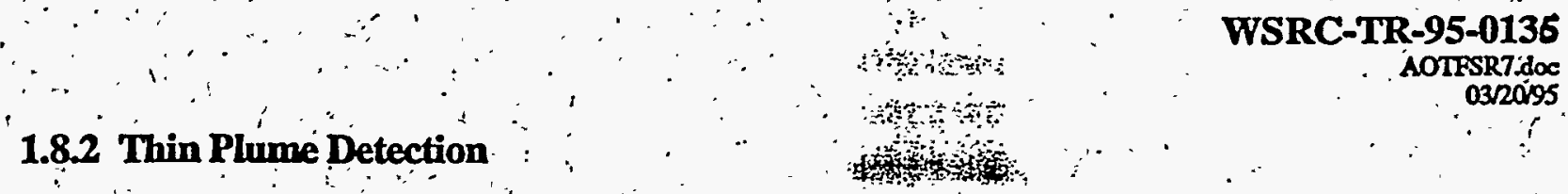

For an optically thin plume, the emissivity is not unity bit has a value which depends on the molecular concentration, optical absorptivity, and plume thickness. From Kirchhoff's law emissivity is equal to absorption. For a gas this law is expressed mathematically as:

$$
=1-\exp (-k) \text { a }
$$

where $L$ is the path length through the plume and $k$ is the spopption coefficient of the gas: It can be shown from the definition of absorbance (the logarithm of the input intensity relative to the output intensity) and the ideal gas law that

$$
\mathbf{k}=22.8 \text { a1 } \mathbf{P}_{\mathbf{v}}
$$

where a1 is the source gas absoinance at $1000 \mathrm{ppm}-\mathrm{m}$ and $P_{v}$ is its vapor pressure in atmospheres.

The plume length is arbitrary. We select a value of at con to make relative comparisons among the numerous source gases because the emissivities then vary considerably among the gases and because the concentration-path length product is conveniently given by

$$
\mathbf{N L}=P_{V} \quad 1000 \text { ppm-m }
$$

Thus, the emissivity, of ammonia, with a vapor pressure of 9,9 atmosphixes, is evaluated at $9,900 \mathrm{ppm}-$ m whereas the emissivity of dodecane, with a vapor pressire of 0.00015 atmospheres, is evaluated at 0.16 ppm-m.

The Clausius-Clapeyron equation relating vapor pressure and temperature can be integrated to relate the vapor pressures at two different temperatures through thie heal of vaporization, $\Delta H_{V}$, to give

$$
\log \left(P_{2} / P_{1}\right)=H_{V}\left(T_{2}-T_{1}\right) / 4576 T_{2} T_{1}
$$

At the boiling point, $T_{b}$, the vapor pressure is exactly one atmosphere and this equation recuces to

$$
\log \mathrm{P}_{\mathrm{V}}=\mathrm{H}_{\mathrm{V}}\left(\mathrm{T}-\mathrm{T}_{\mathrm{bp}}\right) / 4576 \mathrm{~T} \mathrm{~T}_{\mathrm{bp}}
$$

Thus, the vapor pressure of an ideal gas can be estimated from its boiling point and heat of. vaporization. The known boiling points for the source gases are given in Table 10.4 Most of the gases

${ }^{4}$ The value for kerosene is an average value and the value for nitrous acid is assumed to be the same as nitrogen dioxide. 
also have measured heats of vaporization. Those which do not have measured values could have their heat of vaporization estimated from the empirical relationshipo

$$
\mathrm{H}_{\mathrm{v}} / \mathrm{T} \mathrm{bp}=21 \text { calldeg mole }
$$

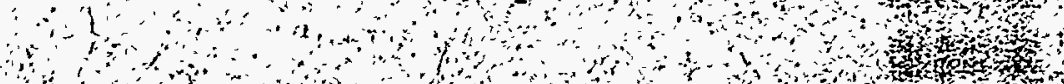

To be slightly more accurate, this ratio was averaged foom an measured values in Table 10 with the result that

$$
\text { that }
$$

$$
\text { 4. }
$$$$
\text { 1. }
$$

Which was used in Table 10 when the heat of vaporization was not kiown

The calculated vapor pressures at $25 \mathrm{C}$ are given 1 table 10 , as well as measured values when known Agreement between the calculated and measured values is quite good The high vapor pressures do not mean that those pressures would actially exist on a vapor plume, but rather that those pressures would calise the plume to rapidy expand into the sumounding atmosphere The net affect on the NL value would be, to first order, the same as if the hifh pressure did exist only in the $0.1 \mathrm{~cm}$ diametex plume Thus, the vapor pressures as given are valid for maling relative compatisons of vapor pressures from different gases Thus volatile gases anch o methane and ammonia are thousands of times more likely to exist in high concentrations than is dodecane or the phosphate gases.

The only difference between a thin plume and a thick plume is the enissivity. Thins, the thin plume detectivity merit factor is given by i)

$$
\mathrm{FMO}_{2}=\mathrm{FM}
$$$$
\mathrm{mol}^{2}
$$

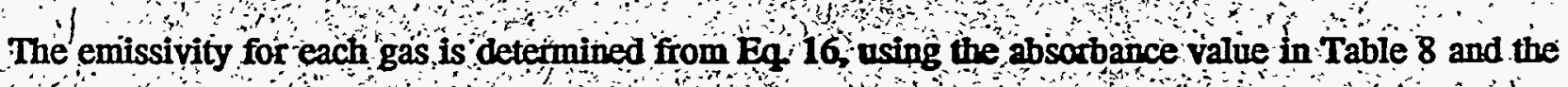
vapor pressure in Table 10. The results are given in Table 11 for a $0.1 \mathrm{~cm}$ diameter plume.




is

Table 10. Calculated and measured unpor pressures oll each gas at 25C.

Chemical Name

Nitrogen oxide.

Methane

Nitrous oxide

Hydrogen chlóride

Hydrogen sulfide

Ammonia

Dichlorodifluoromethane

Sulfúr dioxide

Butane

Nitrogen tetroxide

Nitrógen dioxide

Nitrous acid

Hydrogén fluoride

Hydrogen cyanide

in-Pentane

Hexane

Methanol

Cárbon tetrachloride

Benzene

2-Butanone

Thionyl chloride

Nitric acid

Trichloroethylene

Toluene

4-methyl 2-Pentanone

Hydrazine

p-Xylene

m-Xylene

Sulfur chloride

Bütanol

o-Xylene

Dodecane

Kérosene

Tributyl phosphate

Dibutyl phosṕhate

Monobutyl phosphate

\section{Tbp}

121:4

111.7

$184: 7$

188.2

213.6

239.8

243.3

263.1

2726

294.3

294.3

294.3

292.6

2992

3092

3419

337.7

3499

3532

352.7

3520

356.2

360.4

383.8

$389: 6$

386.7

$411: 5$

412.3

408.8

390.9

417.6

489.5

523.

562.2

613.2

664.2

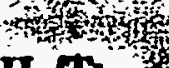



Kcal/deg mole

Pressure in Torr

Cal.

Meas.

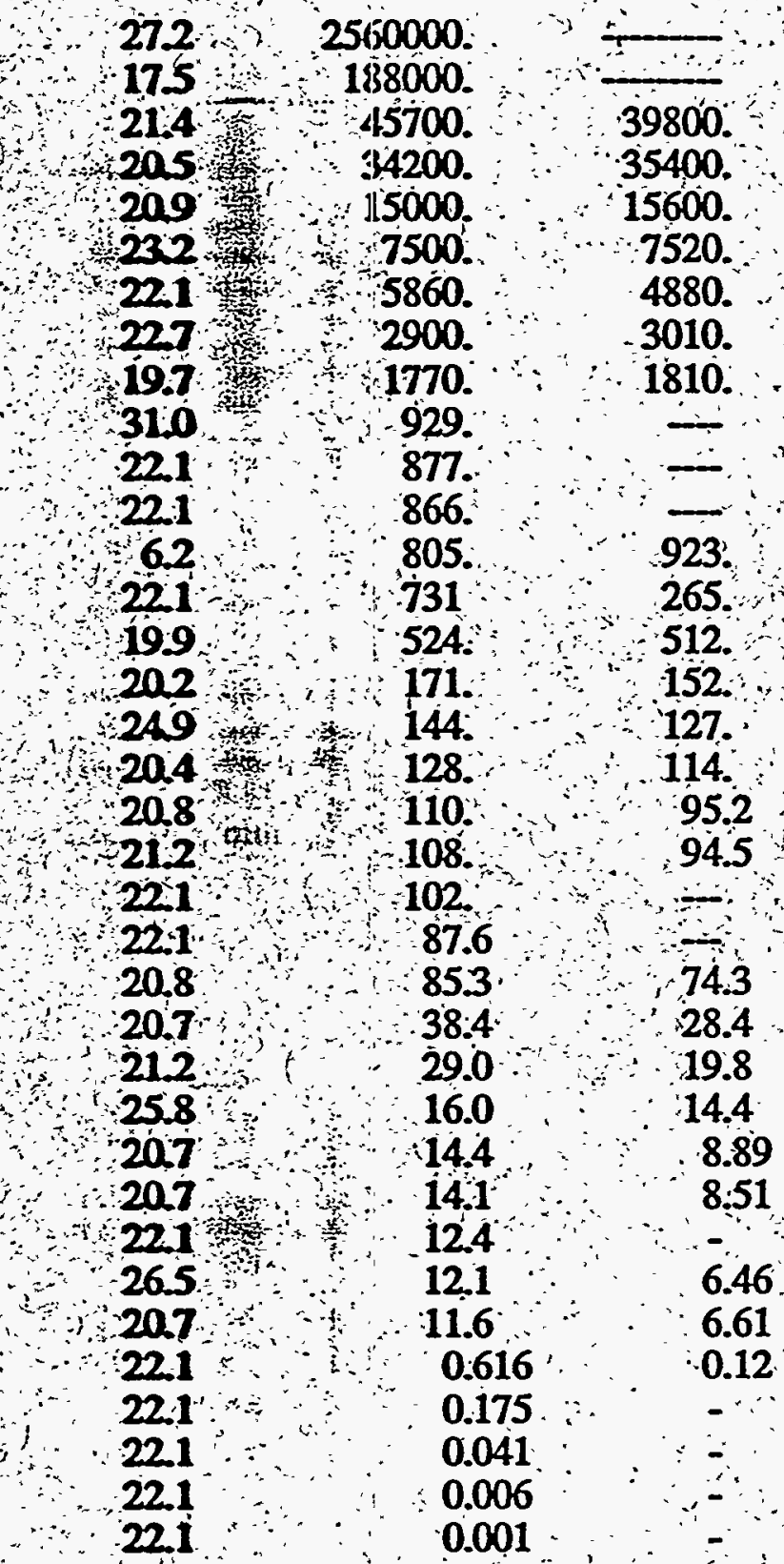

2

t?

max

i2: $\div:=$ 
Table 11. Detectivity merit factor for a thin gas plume at 25C.

Chemical Nạme'

Nitrous acid

Carbon tetrachloride

Ammonia

Dichlorodifluoromethane

Nitrogen tetroxide

Sulfur dioxide

Trichloroethylene

Methanol

Nitric acid

Nitrogen dioxide

Butane

2-Butanone

n-Pentane

Nitrogen oxide

Hydrogen chloride

Nitrous oxide:

m-Xylene

Benzene

p-Xylene :

Hydrazine

Methane:

Toluene

Hexane

Butanol

4-methyl 2-Pentanone

Sulfur chloride

Tributyl phosphate

Thionyl chloride

Hydrogen cyanide

Dibutyl phosphate

Monobutyl phosphate

Kerosene

Dodecane

o-Xylene

Hydrogen sulfide

Hydrogen fluoride
Emissivity

MF2 3is

oing

insta

arseds

s,fes

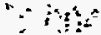

6.451

6.168

5.242

2.449

1.626

1.232

1.186

0942

0.697

0.690

0.434

0.210

0.172

$0: 167$

0.146

0.138

0.106

0.073

0.069

0.043

0.032

0.015

0.015

0.014

0.013

0.007

0.003

0.001

0.001

0.000

0.000

0.000

0.000

0.000

0.000

0.000 
The FM2 figure of merit is the best one for a relative panking of the source gases. Thus, under these conditions, ammonia' is four orders of magnitude more likely to be detected than hydrogen fluoride and 72 times more likely to be detected than berone In fact all gases emitting in the midinfrared are considerably less likely to be detected thin goses emitting in the far-infrared.

\subsection{CONCLUSIONS}

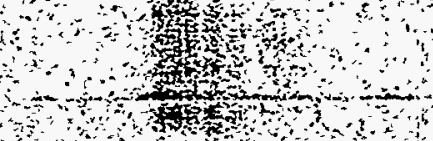

There are several conclusions which can be drawn fonm this analysis. The most important ones are

Relative detection probabilities for thin plumes at 25 c vary from 6.45 for nitrous acid to 0.0004 for hydrogen fluoride with most tag line waveleothe below 8 fun having low probabilities of detection

The top ten gases which have the highest probahility of detection are:

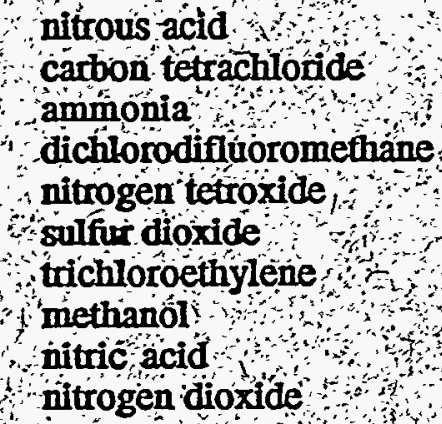

Spectroradiometer resolutions larger than $0.2 \mathrm{~cm}-1$ decrease the measured absobance of

inarrower spectral lines but have little effect on broad lines or oja closely spaced narnow lines.

Without atmospheric absorption, source gas absomanoes at 1000 ppm-m vary from 8.842 for phosphoryl chloride to 0.003 for hydrogen sulfide

Tag line absorbances at $1000 \mathrm{ppm}$-m vary from s6os for tributyl phosphate to 0.002 for hyớrogen sulfịde.

Equilibrium vapor pressures vary from 336 atmospheres fór nitrogen oxide to $1 \times 10-6$ atmosphéres fór monóbutyl phosphate.

Relative detection probabilities for thick plumes at $25 \mathrm{C}$ vary from 8.12 for nitrogen dioxide to 0.0005 for hydrogen fluoride with all tag line wavelengthis below $8 \mu \mathrm{m}$ having dramatically lower probabilities of detection.

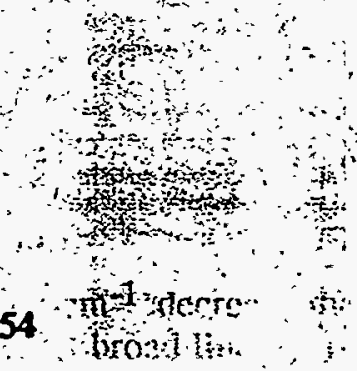




\section{SYSTEM DESIGN AND ANALYYSIS}

\subsection{AOTF PERFORMANCE ANALYSIS}

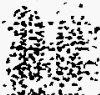

The major isk element in the system is the AOTF and in general the resolution and efficiency are degraded due to crystal quality limitations At low resolution the crysal quality limitations are less restrictive, and the AOTF can approach theoretically limited performanes This is illustrated by the measured rêsponse of a noncolinear TAs AOTF to a $10.6 \mathrm{~m}$ laser beam as shown in Figure 20 . This AOT has an interaction length of $15 \mathrm{~cm}$ and a calculated resolution of $75 \mathrm{~cm}-1$. The resolution was measured by sweeping the AOTF response over the hiser bine and the theasured resolution was $79 \mathrm{~cm}^{-}$ 1 and the response curve very nearly matche the theoretical sinc 2 response function The efficiency was measured as $2 \%$ with 02 W/cm of applied acoustic fnensity, which closely matches the predicted value of 0.224 W/ $\mathrm{cm}^{2}$ at this efficiency, Therefore at low resolution, the AOTF has nearly theoretically limited performance.



Figure 20 - Response of low resolution AOTF showing nearly theoretically limited performance.

At higher resolution, the TAS crystal quality limitations become mote severe This can be seen from the collinear AOTF response to the $10.6 \mu \mathrm{m}$ laser beam as shown in Figure 21. This AOTF has an interaction length of $5 \mathrm{~cm}$, and was operated in a double pass configuration and the input and output beams were separated using birefringent reflection from an internal wedge angle in the $\mathrm{AOTF}$. The 


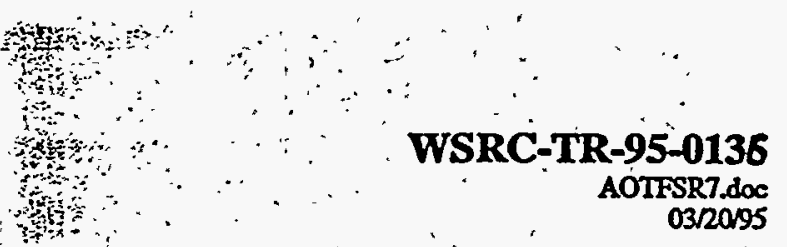

calculated resolution for this AOTF is $1 \mathrm{~cm}^{-1}$, and the efficiency should be $50 \%$ at $0.5 \mathrm{~W} / \mathrm{cm}^{2}$. The measured resolution was $2 \mathrm{~cm}^{-1}$ at an efficiency of $10 \%$ at $0.5 \mathrm{~W} / \mathrm{cm}^{2}$. The resolution was therefore half the predicted, and the efficiency was less than a quarter. These results are consistent with having an interaction length that is half the actual length, which probahly indicates that crystal quality limitations are reducing the effective length by $50 \%$

The design was based upon these measured values which were sufficient to produce excellent sensitivities for gas detection Should a better quality $A$ OTF be produced the sensitivities will improve over the calculated design values, and it is possible that the sensitivities could improve as much as a factor of five for a theoretically limited AOTF.



Figure 21 -Response of high resolution TAS AOTF with acceptable, although not theoretically limited performance.

\subsection{SYSTEM LAYOUT AND COMPONENT SETECTION}

The system design objective was to operate on both the 2-5 $\mu \mathrm{m}$ and $8-12 \mu \mathrm{m}$ bands, and several design concepts were examined. Design tradeoffs for the AOTF filter were conducted; in which either separate AOTFS could be used for the two bands, ar a single AOTF with special beam splitters to direct. the output to the detector arrays would be designed Both concepts were feasible, although the single AOTF system involved considerably more risk Not only were the chromatic beam splitters lossy, but the transducer for the AOTF would have to cover two separate frequency ranges.

The AOTF must have a resolution of $2 \mathrm{~cm}^{-1}$ to adequately resolve the spectra, which requires the use of a collinear AÓTF. For a collinear TAS AOTF, the frequency rarige for the 8-12 $\mu \mathrm{m}$ band is 15 to 
$24 \mathrm{MHz}$, which is a bandwidth covering $46 \%$ of the center frequency, and is easily achievable. For the $2-5 \mu \mathrm{m}$ band the frequency range is 38 to $95 \mathrm{MHz}$, which covers $86 \%$ of the center frequency and although more difficult than the long wave band is still feasible In order to cover both bands with one transducer, the transdicer thiches could be adjusted to poduce the pdmary resonance for the $8-12 \mu \mathrm{m}$ band and the third order resonance could be used for the 25 um band Another possibility is to apply two separate transducers in sandwich stack to the AOT, each of which would be resonant separately over the two bands Both of the approaches are risky, and would require some development In conjunction with the added losses of the special beam geltters, it was decided that two AOTFs would be the least risky approach and the design proceeded along having essigntally two separate AOTF and imiaging systems.

A layout drawing of the spectromete system design is shown in Figure 22 , and it consists of separate AOTFs for the $2-5$ and $8-12 \mu \mathrm{m}$ systems, both of which have 2 resolution of $2 \mathrm{~cm}^{-1}$ The systems are linked with a common optical input axis and the two polayization states of the input beam are separated and directed into the individual systems Although separate parallel apetures could haye been used for the two bands, it was decided to have a common boresighted input axis This allows for the use of a single telescope to change the field of view simultaneously for both systems.

The A OTF interacts with the input beam, and the polatization of the selected passband is rotated 90 by the AOTF The signals are then refiected off the beam splitters and into the lR cameras A wide range of camera systems were examined, including staring and scanned arrays cooled and room temperature detectors, and commercial and fabricated systems The criteria used in evaluating the cameras were (1) having an optical throughput that could be matched lirectly to that of the AOTF, (2) having the best sensitivity and spectral range, and (3) being affordable Under these conditions, the optimum choices were the Cincinnati Electronic IRC-160 Insb camera for the 2-5 jum band, and the Inframetrics 760 system for the $8-12 \mu \mathrm{m}$ region. 


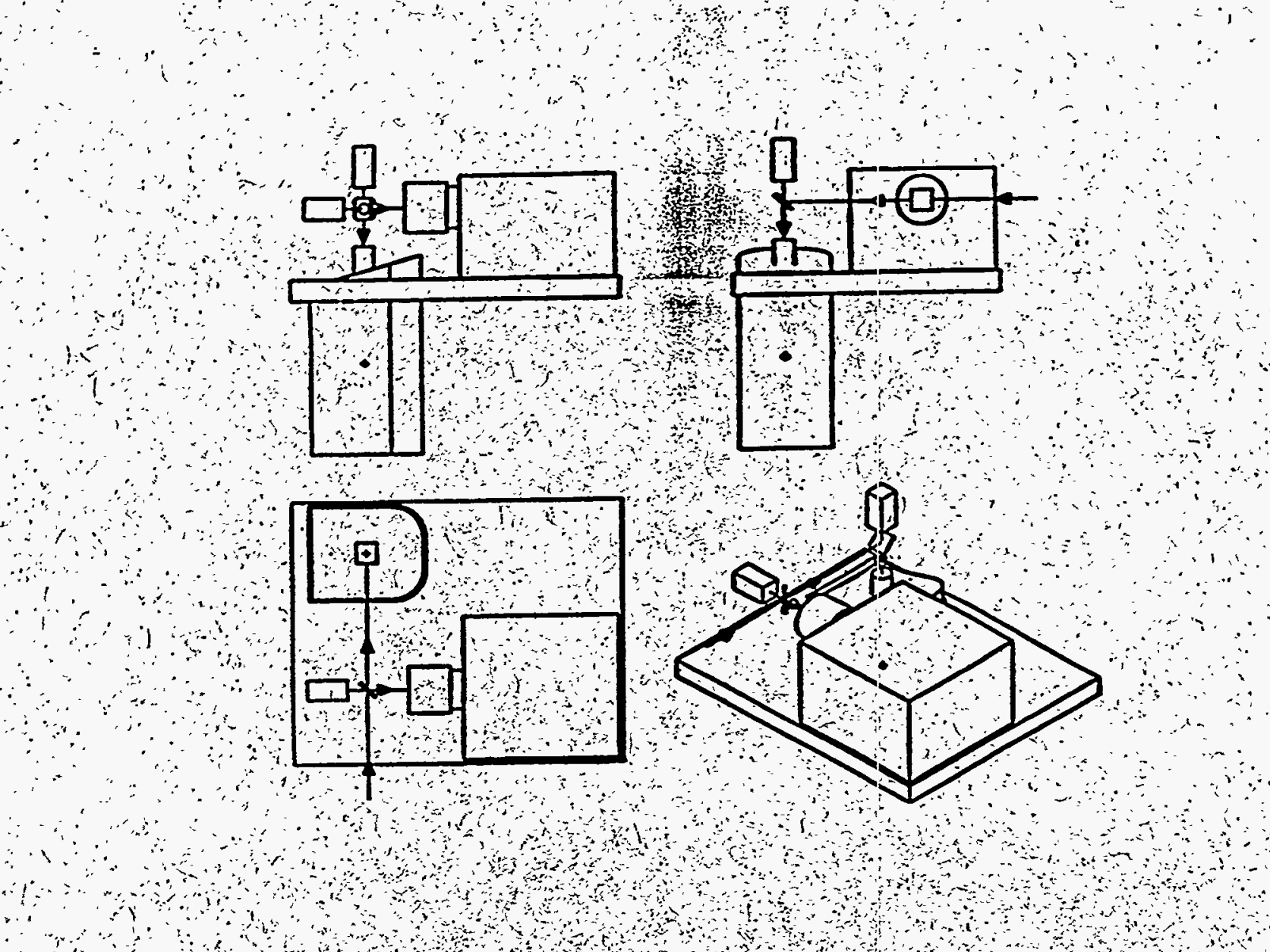

Figure 22 Layout design of dual bond AOTF ingaig spectraradiometer

The Cincinnat Electronics IRC 160 is a 120 a 160 staring InSb array with an NET of $0.025 \mathrm{~K}$ a spectral range of $2.2-4.6$ ja 12 bit digital output and 60 Hz framing rate The $182 \times 13.7$ field of view with a 25 mim input lens also matches very well to the throughput of the AOTF, which is 17 with a 1-inch aperture.

The Inframetrics 760 camera for the $8-12 \mu \mathrm{m}$ band is a scanned HigCdTe system with a NET of $<$ $0.2 \mathrm{~K}$, a 20 x 15 field of view with 1 inch optics, and a $60 \mathrm{~Hz}$ framing rate over an equivalent field of $194 \times 200$ pixels. The scanning is done with a pair of galvometric minors, which are rugged and reported to have a lifetime of several years of continuous operation The output is available in digital form, and a data recorder is avalable as an option This recorder, refered to as the $D^{*}$ STAR system, is incorporated into a high-speed industral computer, with 2.3 Gbyte hard drive This system is capable of directly storing up to 20 minutes of video datain real time, and it can then be used later to analyze the information.

Both of these cameras utilize miniature Sterling coolers for the detector, which avoids the use of liquid nitrogen. They are also compact, rugged, and operate quietly. The Inframetrics 760 was also 
judged as being safer and lëss sensitive to movements than some of the competing scanned systems which use high-speed spinning polygonal'mirrors.

\subsection{AOTF AND ASSOCIATED POWER SUPPLY}

The AOTF was designed to have a 1 inch aperture, $2 \mathrm{~cm}^{-1}$ resolution, and an efficiency as high as possible. To achieve maximum resolution, a collinen Aorf must be used in order to maintain a reasonable aperture dimension, since a noncollinear design will greatly reduce the aperture due to vignetting associated with the off-axis geometry. The resolution of a collinear AOTF is given by

$$
\Delta \lambda=1.8 \pi \lambda_{o}^{2} /(b L)
$$

where $b 2 n, L$ is the interaction length, and $o$ is the FWHM of the passtiand. With a resolution of $\mathrm{o} / \mathrm{o}^{2}=2 \mathrm{~cm}=1$ the theoretical interaction length assuming perfect crystal quality is $2.2 \mathrm{~cm}$.

For à transmission $\mathrm{T}_{0}$ through a collinear AOTF, the relationship for an ideal crystal is given by

$$
T_{0}=\sin ^{2}\left[\pi^{2} M_{2} I_{a}^{2} L^{2}\left(2 \lambda_{0}^{2}\right)\right]^{12}
$$

where $\mathrm{I}_{2}$ is the acoustic intensity at the transdicer, and $\mathrm{M}_{2}$ is the acoustic figure of merit At $10 \mu \mathrm{m}$ with an interaction length of $2.2 \mathrm{~cm}$, TAS will give $50 \%$ thearetical trausmission efficiency at an

acoustic intensity of 2.3 W/cm 2 which is a high although practical value

$\therefore$ The field of view of a collinear AOTF is symmetrical in the polar and azimuthal directions, and the solid acceptance angle is given by $(0 / 0)=n^{2}$, which is identical to that of an etalon having a refractive index of $n$. At $10 \mu \mathrm{m}$ and a resolution of $2 \mathrm{~cm}^{-1}$, the FWHM acceptance angle for TAS is about 17.

A block diagram of the system control and if power generation is shown in Figure 23, where the if frequencies for the AOTF are produced by a SEITEQ ADS432-203 frequency synthesizer board, which is under the control of the computer through a VME controller. The temperature of the AOTF is also. sensed by a thermistor; and adjustments are made in the if frequency to compensate for temperature effects, which are needed to accurately track the spectra

The temperature dependence of the AOTF passband can be obtained from the tuning curve, which: is given approximately by

$$
f_{a_{1}}=\left(V_{d} \Delta n\left(\lambda_{0}\right)\left(\sin ^{4} \theta_{i}+\sin ^{2} \theta_{i}\right)^{1 / 2}\right.
$$




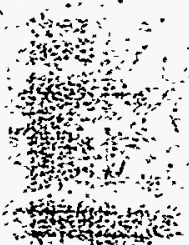

WSRC-TR-95-0136

AOTTFSR7.doc

03/2095

where $V_{a}$ is the acoustic frequency, $\Delta \mathrm{n}$ is the birefringence o is the vacumm optical wavelength, and is the design incidence angle. The temperature dependence is given by the derivatives

and

$$
f_{a} / T=\left[f_{a} /\left(V_{a}\right)\right]\left(V_{2}\right) / \hat{T}
$$

$$
\mathbf{T}=\left[0 /\left(V_{\mathbf{a}} \mathbf{n}\right)\right]\left(V_{2} \mathbf{n}\right) \mathbf{T}
$$

For the collinear design TAS AOTF, the mumerical value to

$$
\mathrm{f}_{\mathrm{a}} / \mathrm{f}_{\mathrm{a}}=\mathrm{o} / \mathrm{o}=-0.001145(\mathrm{~T})
$$

where $T$ is in degres Kelvin Therefore at $10 \mu \mathrm{m}, 2,7 \mathrm{~K}$ temperatue change will shit the passband by $2 \mathrm{~cm}^{-1}$, which will require a compensating frequency change of $36 \mathrm{kHz}$
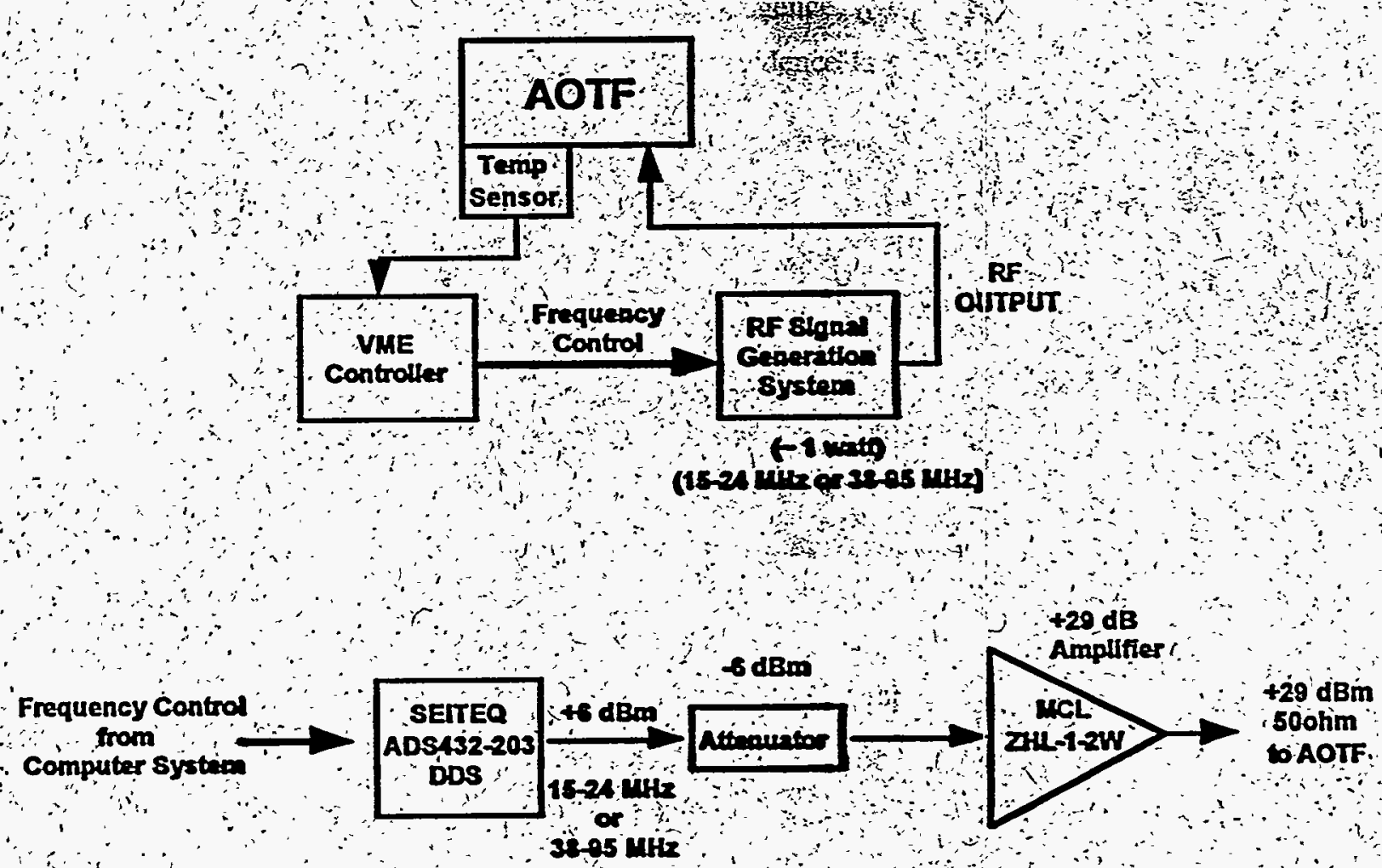

Figure 23. Block diagram of spectrometer control and rf generation subsystems 


\subsection{SIGNAL PROCESSING AND SENSITIVIXY ANAIYSIS}

After storing the image frames, the data will be processed at a rate of about 5-10\% of the collection time The basic processing procedure is to add trames and groups of pixels to increase the signal to noise (S/N), and then to difference the appropdiate frames to obtain the spectral content. The $S / N$ will incresse as the square root of the number of added frames and pixels, and the temporal and spatial resolution will be degraded just enough through this procedure to obtain the required sensitivity. The locations of the species identified by this pocescing on then be fdentified on the original image by color dots, or other such dentification In this way, the gas species will be identified on a high resolution image scene.

thy

The sensitivity of the system design was analyzed using the NET specified by the cameras, along: with the AOTF and system parameters This procedure is pore direct than starting with basic system parameters, and gives a simpler, and generally more accurate analysist. The various system parameters, such as the detector $D^{*}$ and camera field of vew are all encompassed by the NET of the camera, and We can directly examine the sensitivity of a single pixel and then apply the addition of frames and pixel groups to increase the sensitivity to the required level

A temperature difference $T$ must exist between the plume and the background being observed through the plume, and the attenuation through the plume ts registered as a change in emissivity: Assuming the emissivity of the background is unity, the signal produced by a single camera pixel is 24

$$
\mathbf{S}=\mathbf{R}\left(\mathbf{A}_{\alpha}\right) 00 \times(\mathbf{T}) \mathrm{L}_{\mathrm{b}} \mathbf{T}_{\mathrm{T}}
$$

where $R$ is the responsivity of the detector element in oits/W, $A_{d}$ is the detector area, is the system transmission, is the solid acceptance angle of the detector element, exp $(-x)$ is the transmission through the plume, and $\mathrm{L}$ is the blackbody spectral radiance in W/cm ${ }^{2}$-sr-jm. The equivalent noise is given by:

$$
N=R\left(A_{d}\right)(T)(L b)
$$

Where $T$ is the NET of the system, and the integral extends over the spectral coverage of the camera. The advantage of using NET is that $R_{\text {ond }} A_{d}$ cancel in forming the $S / N$, which simplifies the calculation and and bases it on reliable system parameters

The minimum sensitivity occurs with $S / N=1$, and using the absoibances of the candidate gases at the specified tag lines, along with an AOTF efficiency of $10 \%$ at a resilution of $2 \mathrm{~cm}^{-1}$; these minimum detectable levels were calculated. An integration time of 1 second per line was used, which is comparable to an FTIR spectrometer, which typically requires about 4 minutes of integration time to 
cover the 8-12 $\mu \mathrm{m}$ range at a resolution of $2 \mathrm{~cm}^{-1}$. The resolution was also degraded to a single pixel filling the entire image scene, which corresponds to the moximum sensitivity, and is also directly comparable to the FTIR, which has only a single point of resolution.

The sensitivity for a $60 \mathrm{~K}$ temperature difference is showin in Table 12 for the 8-12 $\mu \mathrm{m}$ band, and the sensitivity for the $2-5 \mu \mathrm{m}$ band under similar conditions is shown in Table 13: It can be seen that the 8-12 band predicts excellent sensitivities for a large pumber of the species, such as, tributyl phosphate, but that the 2-5 $\mu \mathrm{m}$ band has a very limited mupber of apecies, and that the sensitivities are very poor. This is due to the blackbody curve falling of mondely at shorter wavelengths, which for room temperature sources produces very little optical power below $3.5 \mu \mathrm{m}$ Feavy molecules also tend to have a much better spectra in the 8-12 um region, which timits ine speries available in the 2-5 $\mu \mathrm{m}$ band to lighter molecules.

Table 12. Predicted detection sensitivities of various candidate gases in the $8-12 \mu \mathrm{m}$ region.

Chemical Name

Tributyl phosphate

Carbon tetrachloride

Nitrous acid

Trichlóroethylene

Ammonia

Dichlorodifiuoromethane

Methanol

m-Xylene

Nitric acid

Di + Monobutyl phosphate

p-Xyléne

2-Butanone

Butanol.

Hydrazine

Nitrogen tetroxide

4-methyl 2-Pentanone

Sulfur dioxide

Benzeñe , um Absorbance

\begin{tabular}{|c|c|}
\hline 680 & 5. \\
\hline 1258 & 5.144 \\
\hline 11.731 & 2.829 \\
\hline 11.7 .72 & 0902 \\
\hline $10.741^{\circ}$ & 0841 \\
\hline 13.09 & 0764 \\
\hline 9.678 & ấ21 \\
\hline 13.020 & 0.525 \\
\hline 11.382 & 0.467 \\
\hline 9.608 & 0.409 \\
\hline 12.575 & a351 \\
\hline 8.552 & 0229 \\
\hline 9.349 & 0206 \\
\hline $10.631^{\circ}$ & 0196 \\
\hline 1294 & 1083. \\
\hline 8.877 & 0.072 \\
\hline 8.597 & 0069 \\
\hline 9.639 & $\mathbf{0 0 6 6}$ \\
\hline
\end{tabular}

$3,8 x+4+4$
Width, cm-1 $^{-1} \quad($ ppb-m)

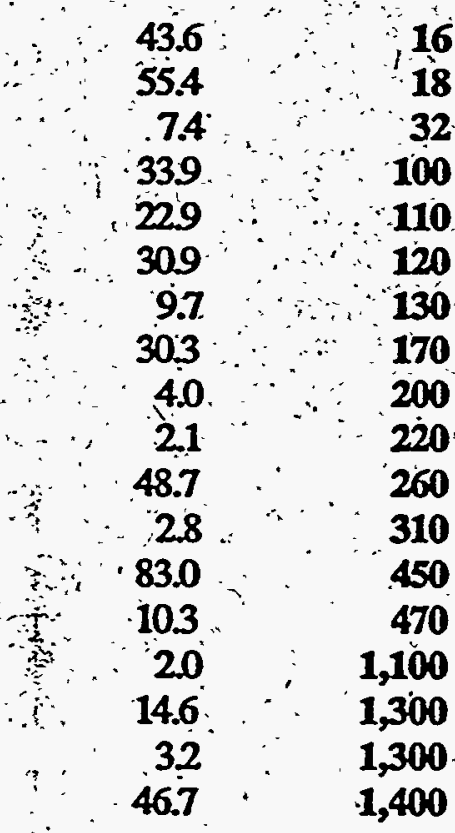

Table 13. Predicted detection sensitivities of varions candidate gases in the 2-5 $\mu \mathrm{m}$ region.

Chemical Name um Absorbance Width, $\mathbf{c m}^{-1}$ (ppb-m)

Methane

Dodecane

o-Xylene

Hydrogen cyanide

Hydrogen fluoride
3.314

3.514

3.361

2999

2499

0738
0135
0
0182
0232
0741

$\because$
$\vdots$
$\vdots$
$\vdots$
$\vdots$

25.8

4.5

16.1

28

5.9
4,500

14,000

16,000

44,000

160,000 
Due to the poor predicted performance in the 2-5. um band it is recommended that the

spectrometer should concentrate only on the 8-12 jim band This band uses the Inframetrics 760 camera, for which there is available the Inframetrice $\mathbf{D}$ sud System which is an industrial computer that can store up to 20 minutes of real-time video data fop the comera an very large drive This computer can then be used to process the stored data ind can also be used to control the AOTF during the data acquisition.
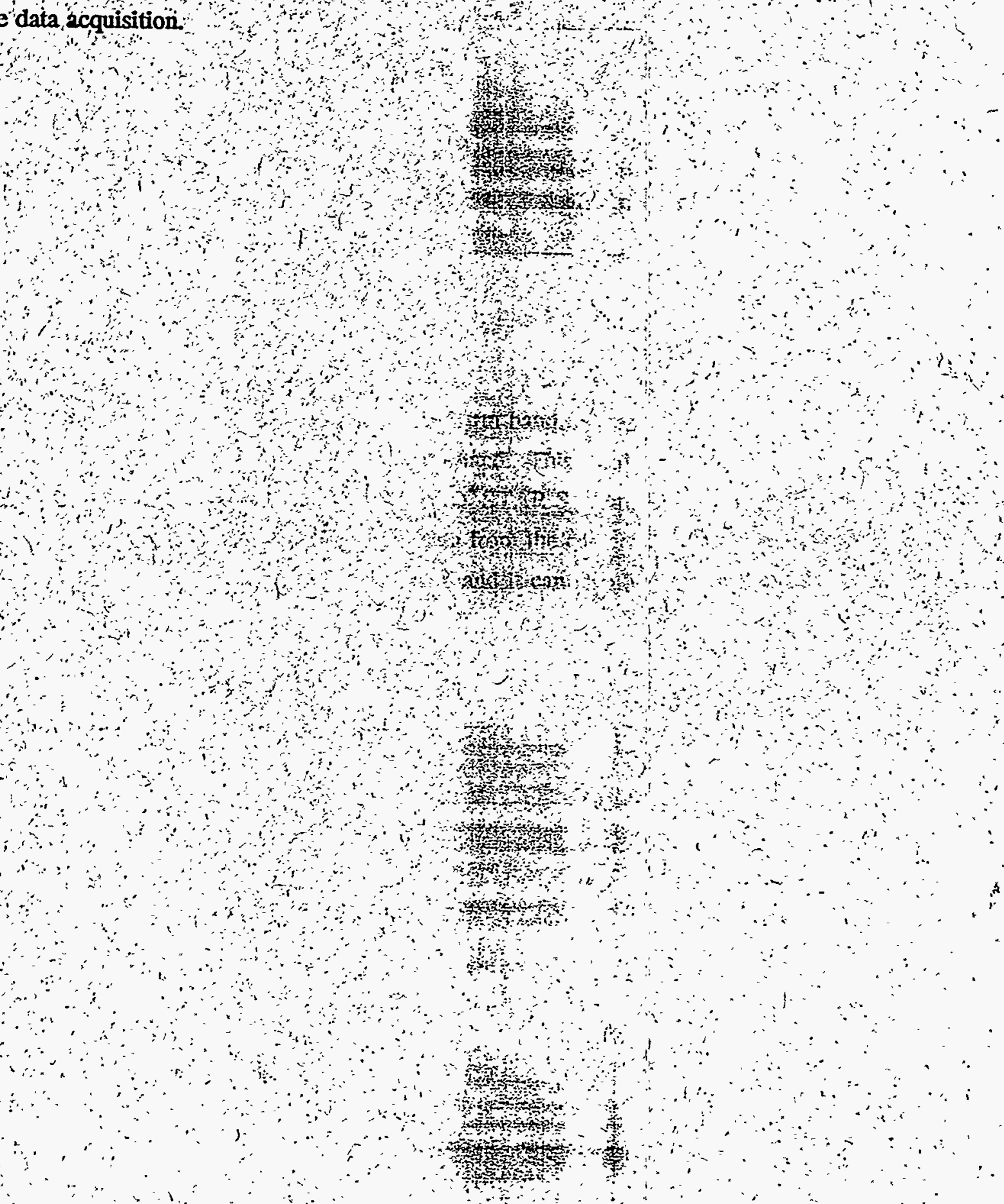


\section{3.' REFERENCES}

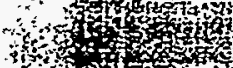

1 E. J. Mccartney, Absorption \& Emission by Atmónpede Gases, Jabin Wiley \& Sons, New York (1983).



2 P. L. Hanst and S. T. Hanst Infrared Spectra for Quantitative Analysis of Gases, Infrared Analysis.

3 P.: Hanst and S.T. Hanst, Gas Measurement in the Fundamental Infrared Region, Infrared Analysis

4 S. Wold, H. Martens, and H. Wold, Thie Multivariate Collopation Problem in Chemistry Solved by the PISS Method, 286, Proc Conf Matrix Pencils, A Rhne B. Kagstrom, Eds., Springer Verlag, Heidelberg (1983)

5. D.W. Marquardt, "An Algorithm for Leastsquares Estimation of Nonlinear Parameters, " J. Soc. Ind. Appl. Math 11:431 (1963).

6 A Savitzy and $M$ J: E Golay Smoothing and Differentiation of Ilata by Simplified Least Squares Procedures,"Anal. Chem. 36: 1627 (1964).

7. H. Press, B.P. Flannery, S. A Teukólsky, and W.T Vettering, Nurnerical Recipes, 2nd Ed, Cambridge University Press, New York (1992)

8. R. Menzies, "Laser Heterodyne Detection Techniques Chap 7, , aser Monitoring of the Atmosphere; E.D.Hinkley, Ed, Spring-Verlag, New York (1976).

9. H R Carlon, The Apparent Dependence of Terestrial Scintillation Intensity upon Atmospheric Humidity," Áppl: Opt $4: 1089$ (1965)

10. J. A Fox, C. R Gainter, and J. L Ahl, Practical Considentions for the Design of $\mathrm{CO}_{2}$ Lidar Systems," Appl. Opt 27: 847 (1988).

11. J.F. Schultz, Los Alamos National Ĺaboratory (Private Communication).

12. A. J. LaRocca, "Atmospheric Absorption, Chap, S, The Infrared Hanitbook, W. L. Wolfe and G. J. Ziessis, Eds., U.S. Govérnment Printing Office, Washington (1978).

13. H. A. Gebbie, W. R Harding; C. Hilsum, A W. Pryce ard V. Roberts; "Atmospheric Transmission in the 1 to $14 \mu \mathrm{m}$ Region, Proc. R. Soc. London A206 87 (1951)

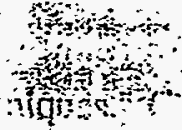


14. G. P. Anderson, S. A. Clough, F. X. Kneizys, J. H: Chetwynd, and E. P. Shettle, "AFGL Atmospheric Constituent Profiles (0-120 km)," Air Force Geoplyysion Laboratory Report AFGL-TR-86-0110 (1986).



15. P. H. Howard and M. Neal, Dictionary of Chemical Name and Symonyms, Lewis Publishers, Ann Arbor (1992)

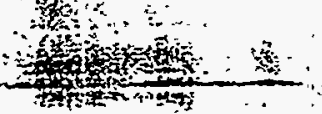

16. N. B. Colthup, L. H. Daly, and S. E. Wiberley, Introduction to Infrared and Raman Spectroscopy, Academic Press, New York (1964).

17. Lab Calc User's Guide, Galactic Industries Corp (1993)

18. R, L. Byer, "Review: Remote Air Pollution Measuremem Opt \& Quantum Electron. 7:-147. (1975):

19: C. L. Wyatt, Rádiometric System Design, Macmillan Pub Co., New Yórk (1987).

20. EG\&G Judson Optoelectronics 1994 Infrared Detectors Catalog

21. S: S. Penner, Quantitative Molecular Spéctroscopy and Gas Emissivities, Addison-Wesley Pub. Co. (1959).

22. F. Daniels and R. A. Álberty, Physical Chemistry, John Wiley \& Sons, New York (1955).

23. CRC Handbook of Chemistry and Physics, 75th Ed, $\mathrm{R} C$ Weast, Ed, CRC Press, Boca Raton (1994).

24. D. F. Flanigan, "Detection of Organic Vapors with Active and Passive Sensors: a Comparison," Appl. Opt. 25: 4253 (1986). 